University of San Diego

Digital USD

1998-03-31

\title{
Observing the Spirit of Resilience: The Relationship between Life Experiences and Success in Higher Education for African- American Students
}

Cheryl Getz EdD

University of San Diego

Follow this and additional works at: https://digital.sandiego.edu/dissertations

Part of the Leadership Studies Commons

\section{Digital USD Citation}

Getz, Cheryl EdD, "Observing the Spirit of Resilience: The Relationship between Life Experiences and Success in Higher Education for African-American Students" (1998). Dissertations. 639.

https://digital.sandiego.edu/dissertations/639

This Dissertation: Open Access is brought to you for free and open access by the Theses and Dissertations at Digital USD. It has been accepted for inclusion in Dissertations by an authorized administrator of Digital USD. For more information, please contact digital@sandiego.edu. 


\title{
Observing the Spirit of Resilience: The Relationship Between Life Experiences and Success in Higher Education for African American Students
}

By

Cheryl Getz

\begin{abstract}
Dissertation submitted for the partial fulfillment of the requirements for the degree of Doctor of Education
\end{abstract} University of San Diego March 31, 1998

Dissertation Committee:

Mary Abascal-Hildebrand, Ed.D., Director John Browne, Ed.D. Lonnie Rowell, Ph.D. 


\section{Copyright (C) 1998}

\section{By}

\section{Cheryl Getz}

\section{All rights reserved}




\section{ABSTRACT}

Some African American students with challenging early life experiences appear vulnerable to failure in higher education. This vilnerability may be exacerbated when educators fail to recognize the relationship between the life experiences of African American students and their academic performance and college success. African American students are challenged further as they attempt to successfully adjust to collegiate environments which often do not validate them or their experiences.

The primary purpose of this study is to investigate this challenge with selected African American students, to learn about how the life experiences of African American students can enhance their success in higher education. A secondary purpose is to learn how these students develop their sense of resiliency and how they think this knowledge can be utilized to promote their own greater self-efficacy and trust. Therefore, the overall purpose is to engage selected students in the development of grounded theory about how educators can learn from African American students about their perceptions of the connections between life experiences and success in higher education. 
This research is qualitative in nature and based on grounded theory methodology, which allows theory to emerge from subject participation: the theory that emerged was generated specifically from the input of the eight African American student interviewees. The information derived from this study may encourage a more creative approach to educational practices in the future, based in part on specific contributions from African American students.

This study confirms that including students in the ongoing dialogue about schooling can be a powerful way to help them examine the ideological nature of their experiences by reflecting on them in a constructively critical manner. The major implication is if the interrelatedness between students' life experiences and academic success were understood more clearly, educators could become more open to enjoying an educational setting in which both students and teachers learn from one another - a setting that better fulfills the fundamental educational goal of preparing students to be successful. 


\section{DEDICATION}

This dissertation is dedicated to my mother, the late Violet W. Getz, who taught me how to love unconditionally, accept others as they are, and trust that with faith, all things are possible. Thank you mom for showing me the way. 


\section{ACKNOWLEDGMENTS}

My sincere thanks to the young men and women who volunteered their time to be a part of this study. Their willingness to share created the foundation for this research, for without their perspective, this dissertation would be meaningless.

Further gratitude is extended to my dissertation committee members: My chairperson, Dr. Mary AbascalHildebrand for her support, encouragement and intellectual guidance. Thanks Mary for your unyielding confidence in me and my work. I am a better person as a result of my experiences with you in the classroom and during the writing of the dissertation. To Dr. Lonnie Rowell for your initial insights and inspiration regarding methodology. Your suggestions were timely, worthwhile and very much appreciated. And finally, to Dr. John Browne, who spent several hours with me sharing his perspective and interest in my topic area. Thanks John, your focus and gentle nudging was a tremendous contribution to this study.

I would also like to thank the young people whom I have coached over the years whose names are to countless to mention. Each have touched my life in various ways. Also, my study group, who provided me with many hours of support throughout this long journey. And my family and dear friends who's love and comfort I felt from miles away. Each of whom 
have been and remain a source of strength in every endeavor I have ever attempted. And finally, a special thanks to my dear friend, Dr. Henry Pugh, whose wisdom, guidance, encouragement and unconditional love helped me to keep my spirits up during those ever so frustrating moments of doubt. I thank you all. 


\section{TABLE OE CONTENTS}

APPROVAL PAGE iii

ABSTRACT iv

DEDICATION vi v v

ACKNOWLEDGMENTS Vii

CHAPTER I: The Problem

Statement of the Problem 1

$\begin{array}{ll}\text { Background of the Problem } & 7\end{array}$

$\begin{array}{ll}\text { Purpose } & 12\end{array}$

$\begin{array}{ll}\text { Significance } & 13\end{array}$

$\begin{array}{ll}\text { Research Questions } & 16\end{array}$

$\begin{array}{ll}\text { Assumptions } & 17\end{array}$

$\begin{array}{ll}\text { Delimitations } & 17\end{array}$

$\begin{array}{ll}\text { Limitations } & 18\end{array}$

Background of the Researcher 18

CHAPTER II: Review of the Literature

$\begin{array}{ll}\text { Introduction } & 21\end{array}$

Historical Conditions $\quad 22$

Slavery and Education 23

Segregation and Education $\quad 25$

Institutional Barriers and
Racism in Higher Education

Sociological Context 31

Socio-Economic Influences $\quad 32$

Socio-Cultural and Family Influences 33

ix 
Reciprocal Learning 36

Resiliency, Trust and Self-efficacy 39

Spirit $\quad 50$

Summary $\quad 54$

CHAPTER III: Methodology

$\begin{array}{ll}\text { Introduction } & 57\end{array}$

$\begin{array}{ll}\text { Methodological Overview } & 57\end{array}$

Qualitative Research 57

$\begin{array}{ll}\text { Grounded Theory } & 59\end{array}$

Symbolic Interactionism 61

Validity and Reliability 62

Research Design $\quad 65$

$\begin{array}{ll}\text { Individual Interview } & 66\end{array}$

$\begin{array}{ll}\text { Group Interview } & 69\end{array}$

$\begin{array}{ll}\text { Data Collection } & 69\end{array}$

Entry to the Population 69

$\begin{array}{ll}\text { Selection of Subjects } & 71\end{array}$

$\begin{array}{ll}\text { Protection of Subjects } & 72\end{array}$

Data Analysis $\quad 73$

Theory of Coding $\quad 74$

Application of coding 74

$\begin{array}{ll}\text { Summary } & 77\end{array}$ 
CHAPTER IV: Findings

$\begin{array}{ll}\text { Introduction } & 79\end{array}$

Students' Sense of Resiliency 81

$\begin{array}{ll}\text { Courage } & 81\end{array}$

Learning to Deal with It 83

$\begin{array}{ll}\text { Proving to Others } & 88\end{array}$

Insight $\quad 91$

Making Choices $\quad 93$

Having a Purpose 96

Educational Goals $\quad 97$

Helping Others 98

$\begin{array}{ll}\text { Trust } & 99\end{array}$

$\begin{array}{ll}\text { Trusting Oneself } & 99\end{array}$

$\begin{array}{ll}\text { Trusting others } & 103\end{array}$

Students' Perceptions of Self-Efficacy 105

Experiences Shaping Perceptions 105

Adapting to Racially Hostile Environments 108

Working Harder and Acting Better 110

Being the Only African American
in Class

$\begin{array}{ll}\text { Feeling the Pressure of } & \\ \text { One's Appearance } & 114\end{array}$

Relating to African American Students 114

Appreciating the Professor and 115

Student Relationship

Not expecting Special Privileges 118

$\mathrm{xi}$ 
Learning about African American Culture

Self-Efficacy as Spirit 121

Wounded Spirit $\quad 122$

$\begin{array}{ll}\text { Hopeful Spirit } & 124\end{array}$

$\begin{array}{ll}\text { Challenged Spirit } & 125\end{array}$

$\begin{array}{ll}\text { Nurtured Spirit } & 128\end{array}$

$\begin{array}{ll}\text { Metanalysis } & 133\end{array}$

CHAPTER V: Summary, Implications, Recommendations $\begin{array}{ll}\text { Summary } & 136\end{array}$

$\begin{array}{ll}\text { Implications } & 143\end{array}$

$\begin{array}{ll}\text { Recommendations } & 149\end{array}$

$\begin{array}{ll}\text { References } & 162\end{array}$

Appendices

A. Interview Questions 177

B. Consent form - Individual Interview 178

C. Consent Form - Group Interview 179

D. Human Subjects Committee Approval 180

E. Recommendations 181

xii 
CHAPTER I

THE PROBLEM

\section{Statement of the problem}

Resiliency, trust and self-efficacy are attributes that many successful students may exhibit (Farrell, 1994; Garmezy, 1991; Henderson \& Milstein, 1996; McMillian \& Reed, 1994; Rutter, 1987; Werner \& Smith, 1992; Winfield, 1991). However, stressful life experiences and disruptive environmental influences, which are often referred to as risk factors, seem to be present in the lives of students who display resiliency. Yet, resilient students can be characterized by their unconquerable spirit, strong sense of self-efficacy, ability to trust and impressive determination to succeed despite the risk factors which may be present in their lives (Gorden, 1995; Wang, Haertel \& Walberg, 1994).

Given that resiliency is found in all groups of people, particularly those in this country who have been oppressed, resilient African American students may have particular difficulty acknowledging their positive attributes, because of the way the United States society in general views this population of students. Thus even with 
the attribute of resiliency in place, these African American students appear more vulnerable to failure in higher education.

However, despite racial discrimination and social inequities encountered by African Americans, there are many examples of African American children from troubled backgrounds who have succeeded in school and have gone on to excel in different professional and career fields (Haynes \& Comer, 1990). Furthermore, some African American students who have grown up experiencing stressful family or community circumstances and who are presently in college already exhibit significant levels of resiliency, due to the difficult task of completing high school given the many obstacles in their lives. However, these students must also shoulder the additional burden of remaining resilient in institutions of higher learning while often experiencing individual and institutional racism on many levels (Flemming, 1984). While individual racism generally consists of overt acts committed by individuals, institutional racism is less overt and thus is often hidden in established policies and practices (Bennett, 1995).

Nevertheless, resilient African American college students may often possess protective factors that contribute to their success. Protective factors, which are the positive counterparts to risk factors, modify a person's 
reaction to difficult life experiences, may reduce the impact of the risk factor and in many instances promote self-efficacy and esteem (Garmezy, 1991; Rutter, 1987). These students continue to believe in themselves and appear able to maintain a strong sense of self-efficacy despite painful life experiences and discrimination. In fact, many African Americans display an inner strength, sense of self and a focus, which I will refer to as spirit, that continues to motivate them. For many African Americans, expressions of a deeper ability to triumph over tremendous obstacles are reflected upon as spirit (Taylor, 1993; hooks \& West, 1991). Perhaps the source of these students' resiliency is selfefficacy and the source of their self-efficacy is spirit, which ultimately has a grand effect on the success of some African American students. Yet many African American students' spirits have been wounded by present as well as past experiences. As a result, not all African American students are able to succeed given the difficult circumstances they must overcome (Flemming, 1984; Garibaldi, 1991).

All students including African American students could benefit from environments that nurture their positive qualities and work to promote protective factors (Comer, 1980). However, while a great deal of research has been done to investigate how life experiences affect or contribute to 
success in resilient children in grades $\mathrm{K}-12$ and how educators can develop protective environments for these students, very little research is available that addresses resilient students in higher education and their specific needs. A theory that is grounded in the specific experiences and perspectives of African American students could prove to be useful for the African American community as well as professionals in higher education.

Many college students may consider that their life experiences are connected to their experiences in school. For example, White students' life experiences are often validated by the messages they receive in the books they read, the teachers they learn from and the visual presence of the white majority that is usually in charge of the institutions they attend. These students may have learned through their educational encounters to value and connect their life experiences with their academic experiences. But if one's life experience outside of school is not validated as a part of their school experiences, then it is possible that this couid work against a student's ability to be successful in our current educational system. Many African American students experience alienation and discrimination in predominately white institutions (Flemming, 1984). Thus, it may be more difficult for African American students to acknowledge or connect their life experiences with their 
experiences in school because their experiences do not appear to be validated in their respective colleges and universities.

Janice Hale-Benson (1990) believes that it is time for us to create educational strategies that are appropriate for African American children:

The education of white children is relatively more successful than that of Black children because the schools were designed for white children. Moreover, the education of white children proceeds relatively more smoothly than that of Black children because they are involved in an interrelated learning experience that compliments their culture. To achieve equal educational outcomes for Black children, it will be necessary to design an educational system that complements rather than opposes Black culture (p. 210).

If African American students are less able to recognize the significance of their life experiences and appreciate their resiliency because of the way that the educational system in the United states is structured, then these same students might find it more difficult to connect their life successes and academic success. Furthermore, teachers and other student development personnel in predominately white institutions may not be able to consciously recognize the relationship between African American students' life experiences, academic performance and college success. In pursuing a more transformational educational attitude, educators must continue to search for ways to effectively contribute to the success of minority 
students. One way is by developing curriculum, programs, practices and policies that recognize, include and validate the unique experiences of all students.

McLaren (1989) agrees and contends, "most approaches to teaching and learning treat knowledge as an isolated product of meaning and abjectly deny the knowledge and social forms out of which students give relevance to their lives and experiences" (p. 227). He further argues that:

Students cannot learn 'usefully' unless teachers develop an understanding of the various ways in which student perceptions and identities are constituted. Teachers need to understand how experiences produced in the various domains of everyday life produce in turn the different voices students employ to give meaning to their worlds (p. 227).

Several scholars (Freire, 1995; Giroux, 1981; McLaren, 1989) believe effective learning ought to be a reciprocal process where students and teachers learn from one another. Educators may be remiss in their inability or unwillingness to learn from their students and to validate the connection between life experiences and academic success. If some African American students themselves are not able to see the connection between their life experiences and success in higher education, their own growth may be stifled. In addition, this may restrict the growth and development of many other students and teachers who could also learn from one another about their respective experiences. Thus, earh 
may be less able to contribute to their own awareness and to others' awareness as well.

Therefore, educators must find ways to understand and significantly support what may lie in the background of the learning processes for African American students in order to promote effective learning for all students. As such, educators may be more able to demonstrate this understanding to other groups of students with the increased awareness that their responses may be, in effect, limiting the success of students in general.

\section{Background}

While there are many studies that attempt to explain the reasons why some students are more able to make a successful transition from high school to college, much research has focused on the reasons why African American students are not successful. It may be that many factors contribute to students' performance. However, research seems limited in areas pertaining to how the effects of students' life experiences, from the students' perspective, affect their ability to achieve success in higher education.

Eigures from The Condition of Education 1995, compiled by the U.S. Department of Education, confirm the discrepancies that exist in the educational progress of African American students. In 1992, 488 of African American 
students enrolled in college the october following graduation, compared to $64 \%$ for White students. In that same year, $13 \%$ of African American students completed four years of college, compared to $27 \%$ of White students. Finally, in 1992, African Americans represented just $9.6 \%$ of the total enrollment in higher education, while White students represented $75 \%$ of the total enroliment. It remains unclear which specific factors account for these discrepancies in educational advancement between white students and African American students.

Some studies indicate that social adjustment and academic performance problems are due to cultural differences in students and their respective communities lOgbu, 1987; Gibson, 1991; McLaren, 1989; Gordon \& Yowell, 1994). Other studies indicate that disruptive family and community environments and lower or underclass backgrounds are responsible for African American students' educational achievement (Ogbu, 1987; Bond, 1981; Coleman, 1969; Blake, Saufley, Porter \& Melodia, 1990). Debates concerning the reasons for the racial gap between Blacks and Whites continue. Ogbu (1978) sums up the debate this way:

Lack of access to adequate school resources is undoubtedly one of the main reasons for the lower school performance of black children, even though other factors like home environment also contribute to the problem... Some studies show that home environment, rather than school environment or resources, affects pupil performance; other studies show just the reverse. (p. 53) 
Ogbu (1978) further emphasizes that there are complex community forces which make it more difficult for African American students to overcome initial school problems. others believe it is the school environment that contributes greatly to the success or failure of minority students (Comer, 1980; Ladson-Billings, 1994). Given these beliefs, researchers continually acknowledge that while some African American students are able to achieve success beyond the high school level, many others are not.

Ogbu (1987) refers to African Americans as involuntary minorities who were brought into the United States through slavery and conquest. He suggests that on the whole, involuntary minorities perceive their reality differently than voluntary minorities (those people who voluntarily came to the United States to live) and the dominant group (Whites in the United States). Gibson (1991) shares a similar view and believes involuntary minorities "have come to believe that the system works for the dominant group but not for them" (p. 365). She further notes that involuntary minorities assume that the problems they encounter in school are a result of racial prejudice and discrimination. This history has had a direct bearing on African Americans' perceptions, interpretations and responses to schooling (Gibson, 1991). 
According to Ogbu (1987), "it is castelike or

involuntary minorities that usually experience more difficulties with social adjustment and school performance" (p. 321). He believes the dominant group usually regards involuntary minorities as inherently inferior. Therefore, there remains in this society a different kind of social system and response to involuntary minorities whom the dominant culture has subjugated for many years.

It is this castelike social system that determines relationships between African Americans and Whites, African American access to education and its rewards, and African American development and responses to education logbu, 1978). Since educational systems in the United States often reflect the interests of the dominant culture (McLaren, 1989; Giroux, 1989), African American students in the United states continue to be in jeopardy of being dismissed by current educational practices.

The civil rights movement created an avenue for African Americans and other minority groups to begin making strides toward more equal educational opportunities. Developments in the education of African-Americans over recent years are directly related to the civil rights movement. From the beginning of the movement in the 1940s, one of the major goals of the civil rights movement was improved education for African Americans. Throughout the decades of struggle, 
the foremost civil rights battles have involved education (Willie, Garibaldi \& Reed, 1991). However, gains have been slow and the struggle to improve educational attainment for African American students continues.

According to Smith (1995), "In 1971, black 25-29 yearolds were only about half as likely as their white peers to have completed 4 years of college, and this gap has not diminished" (p. 18). Garibaldi (1991) expresses concern and reports:

Between 1977 and 1984, the number of black students who graduated from high school increased by 26 percent. Unfortunately, the proportion of blacks going to college decreased by 11 percent between 1975 and 1982 (American Council on Education). In 1976, blacks represented 9.6 percent of the total enrollment in U.S. colleges compared to 8.8 percent in 1984 (p. 94).

If we continue to be negligent in our efforts to recognize and acknowledge the reasons for some of the discrepancies (compiled by the U.S. Department of Education) between African American students and other students in higher education, we may be contributing to the deterioration of the human condition.

Blake, Saufley, Porter and Melodia (1990) discuss the implications drawn from One Third of a Nation, a Report of the Commission on Minority Participation in Education and American Life published in 1988. The report states, "with a growing proportion of the American population made up of minorities who are victimized by economic and social decay, 
further declines in minority progress will lead to declines in national progress" (p.2). Educators must continue to seek meaningful ways to transform education or the shape of society and its future will continue to be at risk.

Teachers and student development personnel remain in vitally pivotal positions, continually challenged to recognize that they can make a difference in the lives of young people, their institutions and the social fabric of this country, or to remain satisfied with current educational practices that do not recognize or validate the experiences of all students. Moreover, scholars and educational researchers such as myself, interested in contributing to this field of study, must be careful not to make grand assumptions when presenting any information that characterizes the significance of a relationship between the life experiences and academic success of African American students.

Purpose

The purpose of this study is to investigate and learn about the life experiences of selected African American students which enhance their success in higher education and to learn about their sense of resiliency and how these students think this knowledge can be utilized to promote their own greater self-efficacy and trust. A further purpose is to engage these students in the development of 
grounded theory about how educators can learn from African American students about their perceptions of the connections between life experiences and success in higher education.

Moreover, it seems crucial for me to seek out those who are current members of the African American student community to enable them to speak out about their experiences as we search together for insights that might make the educational system more responsible and responsive to the needs of all students.

Significance

A significant aspect of this study is that it includes African American college students as subjects, so that we can learn from them how professionals in higher education can be more responsive to their needs as well as the needs of other marginalized students. Many educators may not be responsive to students' needs because they are not able to recognize the connection between a student's life experiences and academic performance and its eventual effect on college success. Some students enter the academy with little preparation and fears of failure, while others seem to be prepared, yet they remain challenged and fearful of failure. Some resilient African American students who come to college despite tremendous obstacles may have strong spirits that enable them to remain self-efficacious. 
However, given the atmosphere of the college campus, even the strongest are challenged by individual and institutional racism that permeates many colleges and universities in the United States. The life experiences of these students are often not validated by members of the university community (Steele, 1992). These students appear vulnerable to failure as they are challenged further to successfully adjust to the collegiate environment.

Schools hoping to educate resilient African American students must first learn how to make them feel valued (Steele, 1992; Comer, 1980). Freire (1970) describes a method of teaching in which students and teachers learn together as the needed pedagogy for those struggling against their own oppression. "In problem-posing education, people develop their power to perceive critically the way they exist in the world with which and in which they find themselves; to see the world not as a static reality, but as a reality in process, in transformation" (p. 64). In this system of teaching and learning education begins with "the solution of the teacher-student contradiction, by reconciling the poles of the contradiction so that both are simultaneously teachers and students"(p. 53). Therefore, a reciprocal relationship can exist between the teacher and the student, whereby learning takes place as a greater understanding develops between them. In this system of 
interrelated views, students are given an opportunity to share their life experiences in ways that could benefit student-teacher learning. When this occurs, students whose spirits were wounded by previous life experiences and those who are continually challenged may feel more valued as these educators seek to understand them.

If educators can understand the interrelatedness between African American students' life experiences and academic success, they may become more open and able to enjoy the experience of learning from students, thus encouraging students to respond to them as they both learn.

Ways must be found to improve opportunities for African American students to be successful and to create opportunities that will help educators and students learn from the unique experiences of each other. As the studentteacher relationship develops and academic success is experienced, students may themselves acquire an increased sense of self knowledge and empowerment and thus strengthen their inner spirits.

With an improved sense of self knowledge, students may become more able to remain self-efficacious as they acknowledge their strengths and learn how to utilize them for future academic pursuits. Academic success usually translates to an improved quality of life for young people. Others can also benefit as empowered students may be more 
Iikely to help create an awareness among other students and adults by sharing how life experiences can translate to academic successes. It is in this context that one can envision the eventual effect student success could have on the society as a whole.

\section{$\underline{\text { Research questions }}$}

The research questions for this study were designed to explore how students view their own sense of resiliency and how this self-awareness contributes to their own sense of self-efficacy and success in higher education. The questions serve as a guide to support a qualitative approach and facilitate participant exploration. The questions are also intended to aid in the use of grounded theory methodology. Grounded theory methodology proposes that the emergent substantive theory is based on the perspective of the participants in the study. Grounded theory further implies that the theory formulated is understood by the participants and usable to others (Glaser \& Strauss, 1967). The following questions were formulated in response to these components of grounded theory methodology:

\#1) What can we learn from African American students about life qualities such as resiliency, trust, selfefficacy, and perhaps other qualities, that may relate to their own sense of success in higher education? 
\#2) What educational theory might emerge to guide teacher and student relationships, given the grounded theory that comes from this study?

\section{Assumptions}

The theory developed will provide the reader with further insights about resiliency in African American students and factors contributing to success in higher education. Other assumptions include:

\#1) Although educators might acknowledge students' life influences, they are not always able to understand how these influences may contribute to success for African Americans in higher education.

\#2) African American students, because of their position as involuntary minorities, may be continually challenged by the perceptions they hold of themselves, and those that others hold of them, which together appear to shape the realities of inequitable education in the U.S. Deimitations

This research is limited to the experiences of the eight African American college students selected specifically for this study. It does not assume that all African American students' perspectives are similar to those of the eight students that participated as subjects in this study. 


\section{Limitations}

The grounded theory that comes from this study is limited to the theory generated by the students' ideas. The ideas generated are based on the collective and individual perspectives of the eight students who participated. In addition, my perspective as the researcher must be considered in the development of the theory derived from this study.

\section{Background of the Researcher}

I chose this population of students with the intention of learning more about their life experiences and how to build upon these experiences to facilitate their success in higher education. I have learned more about resiliency and the reasons for African American students success in higher education. As an educator, I hope to continue to learn and explore how to apply what I learn for the benefit of others.

I received my Bachelor's degree in Physical Education from the University of Cincinnati in 1982, where I was also a member of the Women's Basketball team. Following graduation, I went to Central Michigan University and earned a Master's degree in Athletic Administration, and I also served as the Assistant Women's Basketball Coach. I left Central Michigan in 1984 to become the Assistant Women's Basketball Coach at the University of Dayton. After 
two years at Dayton, I went to George Washington

University, and I was the Assistant Women's Basketball

Coach there for one year. I became the Head Women's

Basketball Coach at Eastern Michigan University in 1987 and remained there until 1992, when I assumed my current position as Assistant Women's Basketball Coach at the University of San Diego.

Throughout my career at several different institutions, I have remained connected to the African American community. I have been mentored by, worked in close relationship with and lived with many African American people. I have also mentored and coached many African American students. As a basketball coach for over fifteen years, I have had the opportunity to learn from young African American women and become friends with them and their families. I have been touched in many ways through these interactions. I have been enriched by this experience and I am grateful for the exposure. I have personally seen their resiliency and especially respect the nature of their struggle to succeed in spite of the barriers they have faced.

I believe I have been able to understand and empathize with others as a result of my own personal struggle with another sort of discrimination as a woman in the maledominated field of intercollegiate athletics. Through my 
relationships, I have been able to make a difference in the Iives of others and I am enlightened by the experience. It is with this in mind that I passionately accept the responsibility to learn more and share this knowledge with others. It is my hope that this research will provide educators and students with further insights about themselves and others so that meaningful educational opportunities are provided for every student who seeks to learn and grow with respect and dignity. 


\author{
CHAPTER II \\ REVIEW OF THE LITERATURE
}

\title{
Introduction
}

From slavery to segregation and so called integration, African Americans have had to face various barriers in many aspects of their lives. Although life in the 21 st century may not include slavery, more subtle barriers and constant reminders of a painful past are still present. History reveals that African American students have not always received a quality education. McLaren (1989) poignantly expresses his own disillusionment with the structural domination of marginalized people in the United States. "The legacy of racism and inequality can be traced back to an earlier America, where official historians have carefully overlooked dimensions of American history, especially those subjugated knowledge's of marginalized and disenfranchised peoples" (p.15). Being responsive to the history and needs of African American students is critical for educators who believe in transforming education so that it more accurately reflects and validates the experiences of oppressed peoples. 
Moreover, institutions of higher learning bear a large part of the responsibility for finding effective ways to educate all students. In order to do this, educators and student development personnel must begin to understand the experiences and the background of the students who come to their institutions (Delpit, 1990; Ladson-Billings, 1994). Historical conditions, community, culture, family structure, socio-economic status, along with literature concerning resiliency, may reveal important qualities about these students. It is my hypothesis that understanding the positive qualities of African American students will enable educators to gain insights about them that enhance their ability to connect with African American students in ways that could promote success in higher education.

\section{Historical Conditions}

To examine educational conditions affecting African Americans, it is important to first understand their history in this country. African Americans suffered through periods of slavery, segregation and discrimination. Although slavery and segregation no longer legally exist in this country, African Americans must live with more subtle forms of racism, discrimination and constant reminders of a painful past in forging a more democratic future. W.E.B. Dubois (1961) eloquently expressed this ideal: 
One ever feels his two-ness, -an American a Negro; two souls, two thoughts, two unreconciled strivings; two warring ideals in one dark body, whose dogged strength alone keeps it from being torn asunder. The history of the American Negro is the history of this strife, this longing to attain self-conscious manhood, to merge his double self into a better and truer self ( $p$. 17).

As educators we cannot change history, but we can begin to understand how our perceptions of history and our propensity for denying others' wholeness contributes to the inequities and subordination of an entire population of people and has a negative effect on us all. Slavery and Education

Since 1619 African Americans in this country have been subjugated by those in power. "African Americans were probably indentured servants in the American colonies until 1640, and perhaps as late as 1650" (Hornsby, 1972, p. viii). Following their period of enslavement, some African Americans became property holders, but those numbers were quite small. Hornsby notes, "by 1840, the free black population in the United States was almost completely disenfranchised. More than ninety percent of the American free black population lived in states which totally, or in part, restricted their right to vote" (p. xii). Even though they were free by law, African Americans were discriminated against in areas such as employment, economic endeavors and education. 
Although discrimination was pervasive, the African American community was politically active and worked hard to educate their young people. In January of 1854 , the first Negro college, Lincoln University, was chartered as Ashmum Institute at oxford, Chester County, Pennsylvania (Hornsby, 1972). In 1865 Congress established a Bureau of Freedom to help freed African Americans survive and to begin educating them. Some of this aid went to the establishment of such colleges as Atlanta University, Fisk University, Hampton Institute, and Howard University (Hornsby, 1972).

Hall and Allen (1989) provide provocative insights concerning race consciousness among African American students. They begin their discussion by reminding readers that life for African Americans in this country has been and continues to be difficult:

The history of Black people in this country reveals contradictions regarding the ideals that form the society's core.... Erom the beginning, Blacks were defined as nonpersons without constitutional rights. As a result, African Americans have been forced to continuously struggle to not only obtain basic constitutional rights (i.e., liberty, justice, and equality) but to regain and define their personhood as well (p. 172).

Considering this historical context, it should be a primary responsibility of all persons, and especially educators, to find ways to build a society that is mutually inclusive in 
order to recover, encourage and embrace those whom we have subjugated for many years.

Segregation and Education

The Civil Rights Act of 1866 made all African Americans citizens of the United States and proposed to give them the same privileges as other citizens (Hornsby, 1972). By 1896, however, due to the Plessy vs. Ferguson decision, African Americans were relegated to second-class citizenship and to what was referred to as separate but equal lifestyles. This decision allegedly proclaimed equality for all people in the United States. Thus, Hornsby (1972) observes, "legalized segregation and discrimination and political disenfranchisement became the order of the day" (p. xviii). Semmes (1992), in his discussions regarding such cultural hegemony and the social reality of African Americans in the United states describes the social construction of segregation. His view supports the notion that the dominant group has the propensity to preserve its power through legitimizing and institutionalizing its practices. Semmes thinks "segregation was a strategy to isolate and inferiorize African people. It was used as a method to facilitate economic exploitation and to maintain political power" (p. 105). He further explains that, "over time, dominant society elites have changed the meaning of segregation for African Americans to fit their political 
needs" (p. 105). In his view, the term segregation "is incorrectly applied to any group-focused effort by African Americans and others to meet the social needs that are not automatically provided to African Americans" (p. 105) as they are to whites.

Today, this attitude penetrates many institutions of higher learning, where efforts to incorporate transformational educational practices or programs may be halted because of various political and institutional interests. Therefore, it remains difficult for African Americans and other advocates to move forward with programs that work to provide opportunities for marginalized students.

As noted earlier, the struggle to provide educational opportunities for African American students was a key element in the civil rights movement. "The chronicle of the civil rights movement in the United States illustrates the centrality of education to the fight of African Americans for equal opportunity and full participation" (LadsonBillings, 1994, p.ix). In Brown vs. The Board of Education (1954), the supreme Court ruled unanimously that racial segregation in public schools was unconstitutional, thereby abolishing the legality of segregation (Hornsby, 1972). "The historic decision over-ruled the findings in Plessy vs. Ferguson (1896) and declared that separate educational 
facilities were inherently unequal" (Hornsby, 1972, p.80). Although legal segregation was abolished, many unequal opportunities and exclusions still exist along racial lines for African Americans in the United States. Institutional Barriers and Racism in Higher Education The gap between Black and White students remains in the United States. The percentage of African American students who continue their education beyond high school lags far behind that of White students. According to The Condition of Education, (compiled by the U.S. Department of Education), in 1994; 49.68 of African American students completed one or more years of college compared to 62.78 of White students; and 16.28 of African American students completed four or more years of college compared to 29.78 of White students. These figures indicate that educational barriers are still in existence for many African American students.

Barriers exist for African American students in the form of institutional and cultural racism that is often hidden in the policies, programs and teaching practices established by Whites in this country (Bennett, 1995). Furthermore, forms of cultural racism can be found in the curricula, campus media and course offerings. There is extensive evidence that African American students feel more alienated than their white peers at predominately white 
institutions (Elemming, 1984). "Because Whites are in control of campus life, institutional and cultural racism, even though it may be unintentional, is likely in the absence of campus-based self-scrutiny and conscious antiracist policy making" (Bennett, 1995, p. 675). And although racist institutional policies and practices may be based on ignorance and can sometimes occur unintentionally (Knowles \& Prewitt, 1969), the effect on African American students is profound.

Bellah, Madsen, Sullivan, Swindler and Tipton (1991) express their views concerning the inability of the educational and occupational systems to make changes that will accommodate people from minority cultures:

Failure or refusal to adapt to them has the inevitable consequence of depriving a person of access to precisely the rewards that in this paradigm make life worthwhile. The numbers of people in our society who have failed in these regards serves as an admonition to make sure one does not join them, but it also, even if subliminally, raises questions about the legitimacy of the whole pattern (p. 43).

It appears that large numbers of African Americans are not included in the dominant culture's educational and societal norms that make up the social fabric established by the majority. "Our present problems are a result of historical conditions, not of some inevitable historical law" (Bellah et al. 1991, p. 50). Resolution of the imbalances in 
society though an arduous task, might be achieved through changes in the educational system.

Some view educational attainment for African Americans as a key to upward mobility in our society. "Since Black Americans have been systematically denied the right to acquire an education, attempts to gain access to educational institutions have always been a central part of the Afro-American struggle" (Hall \& Allen, 1989, p. 174). In the current educational system, African American students struggle to gain access, fit in and remain academically focused because of hegemony in the educational institutions (most of which are predominately white) which resist reforms to racism (McLaren, 1989).

Providing students with an environment that is nondiscriminatory may lead to greater educational outcomes. Colleges and universities whose programs, policies and teaching practices that integrate the perspectives of minority students create less hostile campus environments (Hall \& Allen, 1989; Cummins, 1993). Being responsive to the needs of all students is essential, responsible and ethical. This responsiveness may result in environments more conducive to learning and personal development among diverse populations of students. Institutions of higher learning could be one of the most significant contexts for giving young African American students hope for a future 
with greater opportunities. "Given the national need, universities and colleges are one of the last hopes for reversing some unfortunate trends in minority education" (Blake, 1990, p. 4).

Some believe that many trends in African American education have historical foundations. "The main factor differentiating the more successful from the less successful minorities appears to be the nature of the history, subordination, and exploitation of the minorities, and the nature of the minorities' own instrumental and expressive responses to their treatment, which enter into the process of schooling" (Ogbu, 1987, p. 317). Historic and ongoing experiences with educational institutions have greatly influenced the attitudes of many African Americans toward education (Lee \& Slaughter-Defoe, 1995; Ratteray, 1990). "A major aspect of the relationship between U.S. educational institutions and African Americans has been the struggle between educational ideology and related policies and practices" (Lee \& Slaughter-Defoe, 1995, p. 349).

It seems there has been little change in the attitude of African Americans in the last decade and this is reflected in the number of African American students who achieve beyond high school: in 1971, $11.5 \%$ of African American students who were high school graduates completed four or more years of college. Twenty years later, in 1991, 
only 13.48 of African American students completed four or more years of college. (The Condition of Education, U.S. Department of Education, p. 72). These are alarming statistics.

Smith (1994) concurs as he reveals other trends:

"Overall, about 30 percent of black high school graduates 16-24 years old were enrolled in college as undergraduates during the late 1980's, about the same as a decade earlier. In contrast, about 38 percent of their white peers were enrolled in college in 1990, up from 30 percent a decade earlier" (p. 15). If attitudes persist and trends in educational attainment for African American students continue, changes in our current educational system appear to be urgent (Boykin, 1994). Many believe leaders in the field of education could improve educational outcomes for African American students by recognizing the importance of reversing these trends and demonstrating their commitment to changing current policies, programs and practices to reflect the needs of an increasingly diverse student population (Nieto, 1994; Giroux, 1989)

\section{Sociological Context}

Along with historical conditions, the current societal conditions present in the lives of some African Americans can contribute to lower educational outcomes. Financial 
concerns and family influences often prevent many young people from considering an education beyond high school. Socio-economic concerns may also affect many African Americans in their pursuit of educational attainment. These and other socio-cultural and family experiences can influence the ways in which African American students achieve success beyond high school and perceive their experiences in higher education. Socio-Economic Influences

Although poverty may be a significant cause of academic failure among African American children, it is by no means the only one. It is one of several factors that serve to limit the educational success of African American students (Haynes \& Comer, 1990; Montgomery \& Rossi, 1994). It is a dangerous business to make generalizations about any group of people. Certainly, there are many people from all walks of life who live in poverty in the United States. The African American students who do live in poverty face financial hardships common to many in the United States. Currently, large numbers of African American students live in poverty in the United states. "In comparison to their White peers, Black students tend to have lower family incomes and parents with lower educational attainment" (Hall and Allen, 1989, p. 175). Similarly, Blake et al. (1990), in response to the analysis of variables in a 1987 
freshman survey, suggest, "when looking at student

backgrounds, we see some significant differences,

particularly among Blacks in family status, and minorities

in general in income and levels of preparation" (p. 9).

Correspondingly, Mickelson and Smith (1989) write

extensively about the social problems facing the urban

Black underclass. They concur with Blake et al.(1990) and

Hall and Allen (1989) and respond:

Virtually no scholar or responsible political figure disputes that the social dislocations plaguing members of the underclass include high rates of poverty, unemployment, disease, drug abuse, incarceration, criminal victimization, leaving school, and poor academic performance (p. 99).

Not all African American students live in poverty, but

those that do may also face additional community

circumstances such as crime and drug abuse. This social

context becomes important when looking at otiner issues such

as the values, goals and attitudes of the students that

contribute to the new environmental challenges they face

when they enter the academy (Blake et al.,1990).

Socio-cultural and Family Influences

Research suggests that cultural differences between African American students and white students may account for the disproportionately high rate of academic failure among African Americans (Boykin, 1994). This perspective, referred to as the cultural discontinuity theory, logbu, 
1997) suggests that African Americans have their own culture with different characteristics and practices than those of Whites in this country. Many schools do not recognize or value these characteristics or strengths of the African American community and this may contribute to their failure in school (Boykin, 1994; Delpit, 1990). If educators are open to learning from students, they may begin to understand the role of culture and community in the Iives of many African American students. The African American community plays an important role in the growth, development and attitudes of its young people. Like other communities, many African American communities in the United states today face problems such as increases in crime, alcohol and drug abuse and unemployment. Teenage mothers and single-parent families are more common today than ever before and this problem is also an issue in African American urban communities.

In opposition to the cultural discontinuity theory, Powell (1989) suggests, "given the socio-cultural environment in which many Afro-American children subside, some of the variables responsible for the disparity in academic performance could be expected" (p. 74). Community forces thus constitute another element in school adjustment and performance problems for African American students (Ogbu, 1987). Given these challenges, academic success 
often becomes a secondary rather than primary goal for some African American students.

The home environment is the primary stabilizing force for many young people. The strong influence of the family in the lives of African American children must not be forgotten. "The minority family is the important agent of socialization, for it is within the family context that the individual first becomes aware of and begins to grapple with the significance of racism and discrimination" (Jackson, McCullough \& Gurin, 1997, p. 254). Factors which militate against full participation of African Americans in the dominant society reaffirm the need for community support systems and for the extended family (Brown, 1983). Nuclear and extended families in the African American community play pivotal roles in the development of their children. According to Sudarkasa (1997), "African American extended families embrace many households, some with two generations, some with three or more" (p. 19). However, the African American family structure has changed drastically over the years. The major change that has occurred in the African American family in the past three decades has been the rise in the number of female-headed households (Sudarkasa, 1997). African American gains in education have stalled at a time when the Black family as an institution has been under severe stress (Wharton, 1986). 
Without the stability of a home environment, many students are vulnerable to school failure. Blake et al. (1990) concur and report, "forty nine percent of the black students who completed the 1987 Ereshman Survey reported they came from two parent homes" (p. 5). This percentage was significantly lower that of all other ethnic groups in the survey. This presents a particular challenge for African American students when they enter the academy (Blake et al., 1990). However, even as African American families struggle to maintain a sense of dignity, stability and structure within their communities, the challenge to overcome additional barriers to higher education can be met, as many students do learn to succeed in college.

Given this knowledge, students who are trying to succeed in the traditional milieu of a college campus may be more successful if educators can understand and learn how to use students' life experiences as positive mechanisms upon which to draw (Nieto, 1996; McLaren, 1989; Boykin, 1994).

\section{Reciprocal Learning}

In Paulo Freire's (1995) concept of problem-posing education, students are not docile listeners; rather, teachers and students communicate with each other to explore and investigate ideas that are valuable to them:

Through dialogue, the teacher-of-the-students and the students-of-the-teacher cease to exist and a new term 
emerges: teacher-student with students-teachers. The teacher is no longer merely the one who teaches, but one who is himself taught in dialogue with the students, who in turn while being taught also teach (p. 61).

In reciprocal learning, the students become teachers and the teachers become learners. Educators who are able to learn from and with students "must be partners of the students in their relations with them" (Freire, p. 56). In this partnership, students and teachers can learn from the unique experiences that each of them bring to the classroom.

No longer is the teacher the authority figure who has all the answers. She becomes an active participant with her students in the educational process and learns to respond to the distinct voices present in the classroom. Maher and Tetreault (1994) agree and believe, "Once teachers begin to view their students also as possessors of authority, the process of knowledge construction changes" (p. 129).

In traditional classroom settings, knowledge is constructed based on the values and norms of the dominant culture. "The dominant school culture generally represents the privileged voices of the white middle and upper classes" (McLaren, 1989, p. 230). Therefore, learning may be difficult for African American students who may not feel connected to the experiences of other students in the classroom. In reciprocal learning, teachers welcome input 
from all students because teachers understand that their own learning is essential to student learning. "Teachers are sensitized and they too learn from their interactions with children whose cultural norms are different from theirs" (Haynes \& Comer, 1990, p. 111).

Learning from the voices of all students is critical to education in the 21 st century. When students learn from each other and teachers learn from students greater trust and understanding develops. All students must be given opportunities to critically reflect, analyze and examine their experiences in ways that promote further learning. McLaren (1989) agrees and suggests:

Teachers must understand that student experience arises from multiple discourses and subjectivities, some of which must be questioned more critically than others. It is crucial, therefore, that educators address the question of how the social world is experienced, mediated, and produced by students. Failure in this will not only prevent teachers from tapping into the drives, emotions, and interests that give students their own unique voice, but will also make it difficult to provide the momentum for learning itself ( $p$. 227).

In classrooms where teachers embrace and value the existing voices, knowledge is constructed in divergent ways because all perspectives are recognized as valuable. "These classrooms demonstrate the capacity to give voice to multiple sources of learning" (Maher et al.1994, p. 163). In the process of sharing, the student-teacher relationship is nurtured and students may feel less inhibited and more 
open to allowing their individual voices to be heard. And since "each individual voice is shaped by its owner"s cultural history and prior experience" (McLaren, 1989, p.230), African American students in these classrooms can make valuable contributions to student and teacher learning.

Resiliency, Trust and Self-Efficacy

Resiliency, trust and self-efficacy are attributes that many successful students exhibit (Farrell, 1994; Garmezy, 1991; Henderson \& Milstein, 1996; McMillian \& Reed, 1994; Rutter, 1987). African American students may be aware or unaware of their own resiliency because of the various ways that resiliency is defined. African American college students who have grown up experiencing stressful or community life circumstances and who are in college, may already display significant levels of resiliency because of the typically difficult task of completing high school given the many obstacles that might exist especially in these environments.

There are many experiences in the lives of these African American students that contribute to their sense of resiliency, trust and self-efficacy. Since many resilient students appear to maintain a strong belief in themselves (Garmezy, 1991; Rutter, 1987), I believe that the source of 
the students' resiliency may be self-efficacy. These qualities may be perceived differently by every student; however, this study attempts to find a theory common among these African American students, since they perceive this quality differently than others who were not raised in similar environments and because of their particular position in our society. Their perceptions of their own experiences and sense of self-efficacy also reinforce many other resilient qualities.

Resiliency is defined in various ways in Iiterature. Among the definitions are those that describe resilient children as able to thrive, overcome and adapt despite various adverse Iife circumstances (Gorden, 1995; Masten, 1994; Sagor, 1996). In addition, Wang, Haertel and Walberg (1994), who have done extensive recent research on resiliency in the lives of children in the inner cities, describe educational resilience as "the heightened likelihood of success in school and in other life accomplishments, despite environmental adversities, brought about by earlier traits, conditions, and experiences" ( $p$. 46). Certain life experiences and environmental adversities are often referred to as risk factors which appear to be present in the lives of children who display resiliency. Risk factors or stressful life events can include any Iife situation that impedes the development of children. 
Along with stressful life events, African American students face additional circumstances that are unique to their culture, their perceptions of reality and their socialization process. African American youth in general face many barriers to academic achievement and success in life. Nevertheless, while some African American youth succumb to these pressures and risk factors, others go on to achieve despite overwhelming odds (Eord, 1994). Students who are able to overcome these barriers appear to be resilient individuals.

The increased awareness of children's coping mechanısms under difficult life circumstances led to the discovery of protective factors that are present in resilient children (Rutter, 1987; Garmezy, 1991). Resilience and protective factors, which are the positive counterparts of risk factors, modify a person's reaction to a situation that in ordinary circumstances may lead to maladaptive behavior (Werner \& Smith, 1992). These factors can also reduce the impact of the risk factors and in many instances they promote self-efficacy and esteem. (Rutter, $1987)$.

Resiliency is often described as a process rather than a set of attributes or traits (Henderson \& Milstein, 1996). Resilient students seem to have developed all or some of the following attributes, learned behaviors or protective 
factors: Self-efficacy (Garmezy, 1991; Rutter, 1987;

Masten,1994; Winfield, 1991), attainment of feelings of autonomy (Brendtro, L.K., Brokenleg, M., \& Van Bockern, S.V., 1990; Garmezy, 1991; Gordon \& Song, 1994) high intrinsic motivation or internal locus of control (Brendtro, L.K., Brokenleg, M., \& Van Bockern, S.V., 1990; Graham, 1989; McMillian \& Reed, 1994; Werner \& Smith, 1992) a sense of purpose and future (Benard, 1991; McMillian \& Reed, 1994) and a basic willingness or ability to trust others outside the family structure who can help them (Garmezy, 1991; McMillian \& Reed, 1994).

Resilient students are often willing to trust others who can help them. (Garmezy, 1991; McMillian \& Reed, 1994). By placing trust in educators, African American students may be more likely to experience success in institutions of higher learning, because they will be more open to seeking out help from others. Educators who genuinely seek to support the academic endeavors of African American students will find ways to develop positive relationships that are based on trust and mutual respect.

In his recently published book, Trust: The Social Virtues and the Creation of Prosperity, Francis Fukuyama (1995) explores the relationship between trust, cooperation and economic performance among people of different cultures. He believes, "a nation's well-being, as well as 
it's ability to compete, is conditioned by a single persuasive cultural characteristic: the level of trust inherent in the society"(p. 7). In trusting each other, people respond collectively and cooperatively, to solve problems and improve human conditions.

Many African Americans in the United States may not trust the dominant culture and the institutions they control. Peter Paric (1994) speaks to this very mistrust that he has felt as an African American in the United States:

A generation ago, most of us African-Americans placed our trust in the American dream which was the goal of the civil rights movement: Full participation as first class citizens in the public life of the nation. For us, that trust was sacred. We have lived to see that sacred trust betrayed once again (p. 439).

One finds many episodes that seem to have left African Americans with the feeling that white people and the institutions that they control cannot be trusted. "This distrust arises from perceptions of past and current treatment of blacks by the schools as discriminatory" (Ogbu, 1987, p. 326). This distrust, Ogbu (1987) contends, "contributes to the minorities' social adjustment and academic performance problems" (p. 333). Furthermore, this distrust, along with other isolated random incidences of racism, may develop a perception among African American 
students that educators consider them inferior to other students.

Trust in the educational system and between students and teachers is critical, for without this trust, students and teachers may not be open to learning from each other and the goals of achieving educational gains for African American students might not be reached. Educators who understand these issues could be supportive by deepening trust among African American students by listening to them and developing relationships of mutual understanding and appreciation. One way to develop positive relationships with the students in classroom settings is by giving them opportunities to critically reflect on their particular positions in society (McLaren, 1989; Nieto, 1994). When this occurs, teachers may learn more about the student and the student may also feel more comfortable sharing information because her experiences are validated by the teacher. Through this reciprocity, a certain level of trust may be developed as students and teachers learn from one another (Eine, 1989; Farrell, 1994). Acquiring trust from the student should not be too difficult for the teacher who shows concern for strengthening the academic achievement of the student (Govindarajan, 1991). The results of this human interaction, sensitivity to individual concerns, reciprocal dialogue and inclusion of all students; is the development 
of a unique sense of trust that contributes to the development of a true community (Blake et al., 1990).

Many resilient students are able to trust others.

However, we can not make the assumption that all resilient students possess this quality. It seems critical for educators to find ways to support and nurture this quality, especially in young people from populations who have been oppressed because these students are more likely to distrust the educational institution and those who control it. Students from disempowered communities are even more likely to distrust educational institutions given the harsh conditions many of them have had to overcome.

students growing up in stressful environments such as these must also trust themselves. The students in this study in particular, trusted their own ability to succeed despite the obstacles they were faced with. In his social learning theory, Albert Bandura places emphasis on one's ability to handle demands in life. It "is the perception that one is capable of doing what is necessary to reach ones goals - both in the sense of knowing what to do and being emotionally able to do it." Moreover, "people who perceive themselves as self efficacious accept greater challenges, expend more effort, and may be more successful in reaching their goals as a result" (Lahey, 1995, p. 472). 
The term perception is key to understanding self-efficacy in African American students.

The perception that a student is capable of accomplishing a given task may be learned from what others say about them or their direct experiences of success and failure (Lahey, 1995). Efficacy beliefs also influence individuals' thought patterns and emotional reactions (Pajares, 1996). Pajares (1996) further notes:

People with low self-efficacy may believe that things are tougher than they really are, a belief that fosters stress, depression, and a narrow vision of how best to solve a problem. High self-efficacy, on the other hand, helps to create feelings of serenity in approaching difficult tasks and activities (p. 544).

Messages sent by the dominant culture could influence the ways in which African American students perceive their own ability to achieve academically. African American youth have historically been confronted with many challenges to their self-concept that have negatively influenced their physical and psychological development (Brookins, 1996). "As a result of their subordinate position, blacks have formed an identity system that is perceived and experienced not merely as different from but in opposition to the social identity of their white dominators" (McLaren, 1989, p. 212).

Therefore, African American students could be influenced by or are forced to adapt to the values, norms 
and expectations of a predominantly white society because the mainstream experience is often characterized by the value system of the dominant culture (Brookins, 1996). When this occurs, African American students may find it difficult to trust others and seek out support in many higher education institutions because educators and other students in the environment may be perceived as hostile and in some instances may be hostile. A lack of belief in environmental supportiveness, according to Gorden (1995) lowers one's self-concept:

A good student who does not believe his or her environment supports his or her achievements loses some belief in his or her own abilities. Ability beliefs are also important. Beliefs about ability determine how strongly a person believes in his or her own capability or skill for accomplishing a goal. This is sometimes referred to as self-efficacy (on line).

African American students who do not believe they are capable of reaching their goals may learn something about themselves through environmental influences in the educational setting or elsewhere, that could contribute to or destroy their self-efficacy. According to Edward "Chip" Anderson (1989), "underrepresented students are more likely to experience prejudice as well as discrimination and alienation. With prejudice comes all of the unfavorable, negative, and demeaning judgments that, if internalized, could negatively affect their motivation, commitment, and self-efficacy" (p. 238). 
If my hypothesis is correct and the source of these students' resiliency is self-efficacy, it may be very difficult for African Americans to remain resilient in institutions of higher learning when they perceive the environment as hostile. Teachers must find ways to understand and translate the experiences of African American students in ways that could promote self-efficacy and thus academic success. "Strategies for improving academic performance among black children are too often undertaken in isolation without adequate attention to the social contexts in which they occur" (Haynes \& Comer, 1990, p. 112). Educators who respect, listen and try to understand the experiences of African American students may be more able to support African American students and contribute to their sense of self-efficacy.

Educators continue to revisit their positions with respect to students raised in stressful environments from students who enter college "at risk" to students exhibiting resilience. Children who start in troubled environments do not necessarily continue having bad experiences (Rutter, 1984). A growing trend is visible in the recent literature with respect to African American students from urban areas along with students who have experienced stressful and often disabling life events. Educational researchers are addressing these students and the issues that affect them 
with positive insights about the strengths they bring to our educational institutions. There is an increased awareness among educational researchers of the need to understand educational resiliency and student resilience. Many researchers criticize the previous models that represent minority youngsters as deficient and lacking educational competence. Current research has begun to "paint a more accurate, positive and constructive profile of city kids and the ways they learn, highlighting student strengths rather than "deficits" (Sautter, 1996, p. 4). Much research is focused on translating negative risk factors into positive educational outcomes (Williams \& Newcombe, 1994; Benard, 1993; MCMillan \& Reed, 1994; Winfield, 1991; Sagor, 1996). Many of the students who live in urban areas are faced with difficult choices everyday. Those students who are able to make positive choices are usually resilient students who exhibit some or several of the protective factors previously mentioned. If professionals in higher education can develop programs, policies and implement effective educational strategies, protective factors such as trust, self-efficacy and other qualities that contribute to the development of resiliency, can be strengthened.

If educators are not conscious of the need to understand African American students, and the importance of acknowledging the social context of their experiences, then 
many of these students may become disenfranchised from the educational environment (Cummins, 1993; Steele, 1992). This will have an effect on the students sense of self, as the lack of validation sends a message to students that they are not valued in the university community (Steele, 1992). The essence of the self for all people is the human spirit (Erankel, 1975). When students feel alienated from the campus community because their experiences are not validated, their spirits are wounded, leaving anger and hurt that may contribute to lack of trust and low self-esteem (Locust, 1988). This is particularly serious for oppressed peoples, who continue to be challenged by institutional racism in higher education.

\section{Spirit}

The African American students in this study describe their own resiliency and perceptions of self-efficacy through the stories they share about their life experiences. Their sense of spirit as the source of self-efficacy comes out in these stories that the students share about their life experiences. It is through these expressions that I was provided with an indication of whether or not a spirit was strong, challenged or wounded by difficult life experiences. Spirit is something elusive and unseen to most. Yet, ones spirit reveals itself through the actions and energy of 
human beings (Locust, 1988). People are usually unaware of the power of their spirit. "Spiritual phenomena may be unconscious or conscious; the spiritual basis of human existence, however, is ultimately unconscious. Thus the center of the human person in his very depth is unconscious. In its origin, the human spirit is unconscious spirit" (Frankel, 1975, p. 31). Spirit, energy and personal power are often one and the same. "Our spiritual task in this lifetime is to learn to balance the energies of body and soul, of thought and action, of physical and mental power" (Myss, 1996, p. 64). Some people may be more able to accomplish this task of balance, while others may not.

"The source of human consciousness, spirit, or power is considered Divine in most religious and cultural traditions" (Myss, 1996, p. 65). However, some do not connect spirit directly to ones religion or religious beliefs. Author and scholar bell hooks (1993) in her discussions concerning African American women, believes strength comes from finding one's spiritual center. She further notes that the spiritual and the religious are not necessarily the same. "Living a life in the spirit, a life where our habits of being enable us to hear our inner voices, to comprehend reality with both our hearts and our minds, puts us in touch with Divine essence" (hooks, 1993, p. 185). 
The energy of spirit is central to ones existence. "Every thought that crosses our minds, every belief we nurture, every memory to which we cling translates into a positive or negative command to our bodies and spirits" (Myss, 1996, p. 67). Managing ones personal power becomes the real challenge for most people. For those that are oppressed, this challenge may be more difficult.

Paulo Freire calls for those who are oppressed to develop a critical consciousness, where people become aware of their own oppression. Freire (1995) discusses "Conscientizacao which refers to ones learning to perceive social, political and economic contradictions, and to take action against the oppressive elements of reality" (p. 18). others can work with people to become more aware. However, this critical consciousness must come from ones inner being or spirit. "By making it possible for people to enter the historical process as responsible subjects conscientizacao enrolls them in the search for self-affirmation" (p. 18). From self-affirmation comes a reinforced spirit which inevitably leads toward ones continued growth and strengthened personal power.

In 1903, W.E.B. DuBois wrote in the prologue of his now infamous book the Souls of Black Folks, "I have sought here to sketch, in vague, uncertain outline, the spiritual world in which ten thousand Americans live and strive" (DuBois, 
1961, p. V). DuBois was referring to the ten thousand African American citizens that lived in the United States early in the twentieth century under great duress. Committed to social reform and the continuing education of African Americans in the United States, DuBois (1961) expresses with great eloquence the vitality of the African American spirit:

Merely a concrete test of the underlying principles of the great republic is the Negro Problem, and the spiritual striving of the freedom's sons is the travail of souls whose burden is almost beyond the measure of their strength, but who bear it in the name of an historic race, in the name of this land of their fathers' fathers, and in the name of human opportunity (p. 22).

Nearly one hundred years later and inequality still exists. Many consider the spirit of African Americans the life force that holds individuals within the community together (Nobles, 1997; hooks, 1993; Angelou, 1986). Nobles (1997) believes spirit is extraordinary important in the development of young African American children:

It is important that African American children understand, respect, and obey the supreme spirit that makes them human. The sense of the supreme being will help African American children realize that there is a power and a will that is greater than all else. The sense of the force will tell them that the power is in us all. Knowing that the force is in them will help them realize that in being the manifestation of the supreme force, they have no limitations. The sense of the supreme being will help them realize that just as the natural path of living plants is to grow toward the sun, our natural path is to grow (in understanding) toward the supreme force (pp. 91-92). 
In Native American culture the spirit is an important element because they believe it is the essence of being (Locust, 1988). When students' cultures, experiences and perspectives are not respected and validated, their spirits may be wounded and thus learning becomes secondary. Educators who genuinely care about the intellectual, emotional and spiritual growth of these young people will search for ways to nurture the spirits of African American students.

\section{Summary}

There is a long history of oppression for African Americans in the United States. From slavery and segregated schools through the civil rights movement, and into the present where inequalities in education remain most evident. "African Americans must confront many unique problems in western culture. One major problem has been that the society and school curriculum are designed to encourage all children to conform and to internalize the values of the dominant culture in order to survive" (Gil1, 1991, p. 3). Because African American students' experiences often differ from the experiences of other students, the result may be they internalize the values of the dominant culture, thus not acknowledging their own significant experiences. In doing this, they may be less 
able to realize their own strengths and impart them to others.

Family, socio-economic status and socio-cultural influences play an integral role in the development of many students. To help foster more productive teaching and learning environments for African American students, it is important to work with students to learn from their individual perspectives and experiences. In order "to construct a more adequate explanation of the variability in the school success of minority children, it is necessary to incorporate the perceptions and understanding that the minorities have of their social realities and their schooling" (Ogbu, 1991, p. 7). To do this, educators must seek a greater awareness and understanding about African American students and their development.

With a greater awareness may come an ability for educators and student development personnel to learn from and understand how to support students in their academic pursuits. "Black student development must not be viewed / approached as deficit development. One approach focuses on the negative experiences that African Americans have in American society and at PWIs [predominately white institutions]; the other approach focuses on the positive traits that connection to the African tradition brings to Black students and their efforts to succeed in an Anglo- 
Saxon structure." (McEwen et al., 1990, p. 434). With this latter approach, teachers can acknowledge and embrace the spirits of these students. Furthermore, educators can strengthen the positive qualities such as resiliency, trust, self-efficacy and perhaps others that African American students may exhibit.

Research designed to hear the voices of young African American students is critical to our understanding of and ability to enhance their school success. By listening to the voices of students, educators can begin to work with students meaningfully to improve the ways in which many African American students view educational institutions and achieve educational success in our society. 
CHAPTER III

METHODOLOGY

\section{Introduction}

To understand the relationship between success in college and African American students' experiences with resiliency, it is important to learn directly from the students what meanings they ascribe to their experiences. This information may in turn provide student development personnel and professors with a greater understanding about the strengths of resilient African American students. This also may help lead to the promotion of academic success and resiliency. Since educators and student development personnel can benefit by learning directly from African American students about their perspective, a qualitative research approach based on grounded theory (Glaser \& Strauss, 1967) methodology, with a symbolic interactionist (Blumer, 1969) perspective was utilized.

\section{Methodological Overview}

\section{Qualitative Research}

Qualitative research literature asserts that the phenomenon being studied is best understood through an 
investigative process involving direct interaction with the participants so that their views are reflected in the data. "In a qualitative approach to research the paramount objective is to understand the meaning of an experience" (Merriam, 1988, p.16). To understand the interrelatedness between students' earlier life experiences and their social and intellectual development in college, it is necessary to discover from the students how they themselves describe and understand these experiences.

This research process presented opportunities to gain knowledge from African American students about the meanings they assign to their life experiences and how this relates to their understanding and educators' understanding of their resiliency and success in higher education. Research designed focusing on voices that have generally been silenced is important in our efforts to improve the quality of education for African Americans and other marginalized students in this country (Anderson \& Herr, 1994; Maher \& Tetreault, 1994). Traditional education in the twentieth century does not adequately reflect the perceptions and views of students who are not members of the dominant culture. Some researchers (Nieto, 1996; McLaren, 1989) believe that further explanations of schooling grounded in students' perspectives are needed so that professors, administrators and policy-makers can better understand how 
teachers fit diversity and student characteristics into the framework of what they (teachers) perceive as appropriate, school-approved behavior (Anderson \& Herr, 1994). Quite often, educators perceptions of reality are dominated by the world view of the Anglo culture. This research is aimed at expanding educators' perspectives by seeking input from students who are underrepresented in many colleges and universities in the United States.

Grounded Theory

"The grounded theory approach is a qualitative research method that uses a systemic set of procedures to develop an inductively derived grounded theory about a phenomenon" (Strauss \& Corbin, 1990, p. 24). The purpose of grounded theory methodology is to gradualiy build a theory based on the information received from study participants, data analysis, and other insights gathered as the investigative process unfolds. According to Glaser and Strauss (1967), this methodology seeks to generate theory that enables prediction, is useful and practical and provides a perspective on a given topic or behavior. The theory derived must fit the situation being researched. In other words, the categories must be relevant, applicable to and indicated by the data under study.

The theory that emerges from the data is grounded specifically in the experiences of the participants 
involved in the study. One of the most powerful ways to bring forth reality is the "development of theoretically informed interpretations" (Strauss, 1978, p. 22). Developing a theory throughout the research process is one way to derive meaning from the realities of the participants. As the ideas unfold, the students' input is critical to the development of a theory that can be used by educators who may be searching for more productive ways to support African American students. Strauss and Corbin (1990) confirm the use of grounded theory in this context and believe that "the theoretical formulation that results not only can be used to explain that reality but provides a framework for action" (p. 22). This method of analysis makes the students' realities key to the development of an educational theory based on their experiences and their perceptions of those experiences.

A good grasp of this theory can help professors and others in higher education understand the characteristic strengths that resilient African American students bring with them to the educational setting. Furthermore, this knowledge may also generate a greater awareness and understanding of the specific issues and barriers faced by African American students. The information derived from this study may result in more creative educational solutions based primarily on input from the students and 
the data extrapolated therefrom.

Symbolic Interactionism

Blumer (1969) contends that using a qualitative approach to inquiry is the only way to understand how people perceive, understand, and interpret the world. In symbolic interactionism, research is focused on the meaning of one's reality based on interactions with others, because interaction is fundamental to human behavior. "People create shared meanings through their interactions, and those meanings become their reality" (Patton, 1990, p. 75). Human beings modify and handle a thing or an event through an interpretive process used they use to deal with various life events. The meanings of these events are conveyed through verbal and nonverbal interactions (Blumer, 1969). Direct interaction throughout the interview process, along with participant involvement, helps the researcher understand the symbolic world of those being studied (Patton, 1990).

I recognize that viewing the experiences of African American students, from one's own limited perspective, is of little significance without reframing what we know through the perspective of the African American students themselves. Using both individual interviews and a group interview provides a solid method for understanding the realities of the students in this study. Merriam (1988) 
suggests that researchers cannot presume to know about all human experiences; therefore, "qualitative research assumes that there are multiple realities - that the world is not an objective thing out there but a function of personal interaction and perception" ( $p$. 17). The perceptions and realities of the students in this study varied. Each responded to questions from individual realities and personal experiences, but the extraordinary similarities of some responses reflected a common perspective stemming from their position as African American students. Validity and Reliability

Methods for assessing the validity and reliability of qualitative research differ from those traditionally used in quantitative research. Merriam (1988) believes "reliability refers to the extent to which one's findings can be replicated" (p. 170). Reliability, therefore, implies that there is a single reality that will provide researchers with the same results in similar studies. However, in studying human behavior and experience, it is important to realize that there are multiple realities that inform the life stories of each individual.

Since there is no single reality in qualitative research methods, Merriam explains that "assessing the isomorphism between data collected and the 'reality' from which they were derived is thus an inappropriate 
determinate of validity" (p. 167). While Merriam defines internal validity in relation to how one's findings match reality, she contends, "validity, then, must be assessed in terms of interpreting the investigator's experience, rather than in terms of reality itself (which can never be grasped)" (p. 167).

When posing a question about human experience, one must be concerned with the participants' understanding of their experiences. Understanding how the life experiences of African American students can be used to help them achieve success in higher education was one of the primary goals of this research. A further goal was to enhance opportunities for those in higher education to find ways to support African American students' social, emotional and intellectual development. The significance of their stories was captured through the interview process. The goal of any interview process is to learn how the participants understand and make meaning of their experiences. If the interview structure works to allow them to make sense to themselves as well as to the interviewer, then it has gone a long way toward validity (Seidman, 1991, p.17). Lincoln and Guba (1985) propose the notions of credibility, transferability, dependability and confirmability as components of trustworthiness, when doing qualitative research. These terms provide researchers with 
greater direction when measuring the reliability and validity of qualitative research. In doing qualitative research, the researcher must show that she has represented the multiple realities of her subjects adequately (Lincoln \& Guba, 1985). The study is credible if participant statements and descriptions of their life experiences are accurate.

Credibility in this study was established by using open-ended questions and two interviews with each participant as well as another method Lincoln and Guba labeled as "member checking." In this study, my preliminary analysis was given to each subject prior to the second interview, and my complete analysis for review and additional feedback.

Transferability or generalizability is difficult to measure in qualitative research studies. "If there is to be transferability, the burden of proof lies less with the original investigator than with the person seeking to make an application elsewhere" (Lincoln \& Guba, 1985, p. 298). The responsibility of the original investigator therefore lies in providing as much empirical evidence from several sources as possible. I chose several methods of data collection for this study. Two individual interviews with each participant, a group interview, the observance of verbal and non verbal behaviors and the literature review 
served as sources of triangulation to enhance transferability.

Dependability and confirmability can be established by utilizing several techniques. In this study, written notes were taken throughout the data collection phase in a separate notebook and on the interview transcriptions as well. These notes, along with participant observations, served as overlapping methods of triangulation noted by Lincoln and Guba (1985) as one measure of dependability. Confirmability was established through the audit trail technique (Lincoln \& Guba, 1985). I solicited critiques throughout the process from four colleagues who served in an advisory capacity. My advisory committee provided frequent interpretations of the data to ensure its consistency and reliability. Members of my dissertation committee acted as additional external auditors as they gave me feedback on my written and verbal data analyses.

\section{$\underline{\text { Research Design }}$}

There are several methods of inquiry used in qualitative research. For the purpose of this study, I gathered data through the process of two individual interviews with each student, informal discussions and a group interview. Before I began to interview subjects, a pilot interview was done with colleagues who served as my 
advisors throughout the procedure. All of the people involved in the pilot interviews were African Americans who were raised in what they described to me as difficult and often hostile environments. A total of four participants assisted with this phase of the research. Several suggestions were made to improve the open-ended interview questions.

The open-ended questions used for the initial interviews were the same for the first four students (Appendix A). After those interviews, I changed some of the initial questions slightly as a result of the input I received from the first four subjects. The questions utilized for the second interviews were again slightly different, as I remained open to change as the interview process unfolded. These questions were designed to reflect individual variations in the participants' responses during the interviews.

Individual Interview

Each of the eight participants were initially contacted by phone. During that phone conversation, I briefly explained the nature of the study. I then scheduled an appointment for a time and place that was convenient for the subject. The interview sites varied. In most instances, we met in a quiet room at the student's school. In some instances, I picked up the students at their homes and 
brought them to the University of San Diego, where I was able to reserve a quiet room very easily. When I occasionally traveled with students, I was able to learn more about them through casual conversations about school, their families, interests, etc. I usually called the subjects prior to the interview day. When I was not able to reach the subjects by phone, appointments rescheduled.

Prior to each interview, I explained the purpose of the study, my interest in the topic area and the reason for the consent form (Appendix B). The participants were then asked to sign the consent form and ask any questions they may have had. All individual interviews were audio-tape recorded. Notes were taken for clarification purposes only.

I began by interviewing each student using an openended interview approach. In this type of interview, "the researcher develops a protocol of general questions that need to be covered; however, the researcher is free to move in any direction that appears interesting and rich in data" (Tierney, 1991, p. 9). This method allowed the students and myself the freedom to explore topics that were not directly related to the initial questions. The first interview with each student usually lasted between forty five minutes and one and a half hours.

Immediately following each session, the tape recorded interviews were transcribed by a third party. I then 
listened to the tape recorded interview and followed the typed transcript to ensure its accuracy. Following this, I wrote a preliminary analysis of the interview. In this analysis, I studied the students' responses and summarized their thoughts and ideas as I understood them. Within a two-week period, I returned the typed transcript and the preliminary analysis to the subject to ensure clarity and exactness in my analysis. This also gave the participants an opportunity to revisit some of the issues that were discussed, before we began their second interview. About one-third of the participants thoroughly read both documents. However, most of the students read the two-page preliminary analysis. Some of the subjects provided additional feedback based on the analysis, others informed me that the analysis was accurate and they had nothing new to add.

The second interview was generally done within two weeks of the first. There were a couple of exceptions to that when appointments were canceled or the transcribed information was not returned to the subjects as quickly. Questions for the second interview were based on the preliminary analysis from the first interview. I developed some questions that became standard for the second round, but many of the questions were specific to the insights and perspectives of each participant. The second interview, 
which generally flowed much easier than the first, lasted from one to two hours.

\section{Group Interview}

At the conclusion of all the individual interviews, a group interview was arranged. Six of the eight participants were available for the group interview. Two subjects had originally planned to come, but situations arose that kept them from completing that portion of the study. All participants were asked to sign a consent form (Appendix C) that addressed the issue of confidentiality and anonymity. Snacks and soft drinks were served and a casual atmosphere was created.

The initial themes that emerged from the data based on the sixteen individual interviews were shared with the subjects during the group interview. I sought their feedback and expanded upon several of the topics during that time. The group interview was videotaped and lasted approximately two hours. The purpose of videotaping was to better follow the comments and the interaction among the subjects.

\section{Data Collection}

Entry to the Population

Contact was initially made to the person(s) responsible for the protection of human subjects at eight of the colleges and universities in the San Diego area. I received 
positive responses from six of the eight people I contacted. I followed through to receive approval at those six schools. One school required a full review by their own human subjects committee; the other schools were satisfied with copies of the initial proposal I had given to the human subjects committee at my home school. After receiving approval, I also contacted people I knew in the African American community who were closely connected with students at each of the eight schools. On several occasions I was given the name of a person at the school to contact. I then sent an informational letter describing the purpose of the study and its implications for educators. One school required that a flyer be given to the appropriate contact person who would in turn pass it along to interested students. I also used this flyer to solicit volunteers from my home campus, the University of San Diego.

I began the data collection phase in May, 1997 and completed it in October of that same year. It was difficult finding students during the summer months, so many contacts did not result in obtaining student volunteers. In one instance a student was recommended by another student who was already involved in the study. Other volunteers were recommended by students that I knew from my previous involvement with African American student groups. Half of 
the students were recommended to me by administrators or professors I was acquainted with before the study began. A variety of colleges and universities in the San Diego area are represented by the subjects in the study: six colleges and universities, two private four-year schools, one state four-year school and three community colleges. Three of the six schools are predominately white and three represent mixed populations: one was predominately Latino, one predominately African American and the third has a very diverse student population.

Selection of Subjects

The eight students selected for this study: (a) were of African American descent; (b) were sophomores or juniors in college; (c) were between the ages of eighteen and twenty-two; (d) were attending a college or university in the San Diego area at the time of the individual interview; (e) had lived through or are currently living in what they referred to as difficult, stressful or challenging life situations; and (f) were willing participants.

For the purposes of this study, the fifth criteria -- living through difficult or stressful life circumstances -- was established by each of the eight African American student participants. Since one of the purposes of this study was to learn about resiliency, I deliberately sought out students who had come in direct 
contact with disruptive elements as they grew up. Obviously, this is not the experience of all African Americans, but the students I spoke with believe they are resilient because of the difficult, stressful and challenging environments they have been exposed to and were able to overcome. The experiences the students described to me included the following: violence in their home and/or neighborhood, drug and alcohol abuse by parents and/or other family members, sexual abuse, homelessness, gang involvement, incarceration, emotional abuse, parents' separation or divorce, single-parent families; and constant moving from one home to another.

The subjects' level of exposure to various disruptive elements varied. Two of the students had limited exposure to disruptive elements during childhood and were raised in stable homes with two parents. The other six had a variety of exposures to factors that could be considered disruptive to one's emotional, social and intellectual development. Protection of Subjects

All guidelines set forth by the University of San Diego Committee for the Protection of Human Subjects were followed. Approval was granted by the committee prior to any data collection (Appendix D). In addition, permission was granted by each school where research was conducted. 


\section{Data Analysis}

Eollowing each interview, I carefully listened to each tape and made notes on the typed transcripts. In addition, I kept notes, memos and journal entries during the six months of the data collection stage. I also continued to read the literature on resiliency and do research related to African American student achievement. This aided in the constant flow of ideas as I began to become immersed in the data.

In grounded theory methodology, data collection and coding shape the data analysis; thus each is an essential part of the analysis process. The approach I used in analyzing the data was the constant comparative method (Glaser, 1967). The purpose of the constant comparative method of joint coding and analysis is to generate theory more systematically by using explicit coding and analytic procedures (Glaser \& Strauss, 1967, p. 102). This method was used to develop concepts and categories that represented the thoughts, feelings, actions and perspectives of the subjects.

Open coding was utilized in the initial analysis to move from descriptive to conceptual ideas. During this step, several concepts emerged and categories were developed. The categories were further analyzed according to properties and dimensions; then by the examination of causal conditions and 
their properties and dimensions through the process of axial coding.

Theory of Coding

Coding refers to the method used to examine and analyze the data. In open coding, data is compared, conceptualized and categorized. Moreover, in open coding, categories are developed that represent conceptual ideas and their similarities in the data. The next phase is axial coding which involves a set of procedures used to make connections between the categories developed in open coding. (Glaser \& Strauss, 1990). During this procedure, the data is further analyzed by examining causal conditions, properties and dimensions. It is through this process that relationships are uncovered among the given categories. Although all processes overlap, the final method of coding -- selective coding -- involves the integration of categories to form a grounded theory. Similar to axial coding, selective coding is done at a higher level of analysis. It is at this point in one's research that core categories are developed that completely encompass the phenomenon under study (Glaser \& Strauss, 1990).

Application of Coding

As the interview transcripts were completed, I searched for themes and similarities in the data. Notes were made in the margins of the transcripts. This procedure was 
especially helpful during the first round of interviews, where I was able to refer to those notes when preparing the preliminary assumptions. I was also able to discuss some of my initial insights with colleagues and members of my dissertation committee.

During the first round of interviews with four of the students, many concepts emerged. From these concepts, twenty-six categories were developed. After the second round of interviews, an additional four categories were added to reflect significant concepts that surfaced. With this information, I then began to code the transcripts using colored markers and identification numbers. After I completed coding two or three of the transcripts, I entered all of the data from each category in a separate notebook. I did this by working with one category at a time and writing down each piece of information that corresponded to that category from each of the transcripts. Since I continued to analyze the data while I was completing the interviews, this process led to several questions that were posed to the students in the second round of interviews.

Once all of the interview transcripts were coded and separated, using the constant comparative method I began to link categories by close examination of similarities and constant exploration of my own assumptions about the data. Eight themes emerged from this continued analysis, and I 
began to compare and contrast data from each of these eight themes. I searched for causal conditions and the properties and dimensions among these conditions to further analyze specific concepts among each of the eight themes. It was during this phase that I was able to look at a specific phenomenon and explore the events or incidents that led to it (Glaser \& Strauss, 1990). For example: in the phenomenon of a student's motivation to succeed (which was a conceptual idea within one of the eight emergent themes), I found two causal conditions: proving to others and proving others wrong. For the causal condition of proving others wrong, several properties surfaced, among which were: making someone else look bad and doing the opposite of what someone expects.

To take this process a step further, I looked at the specific dimensions of motivation, such as highly motivated, slightly motivated -- all the way down to never motivated. With continued reflection, data comparisons and further exploration of relationships among the categories and the concepts within them, four major themes emerged: courage, insight, trust and student perceptions. Strauss and Corbin (1990) explain that it is often necessary to formulate and commit to a story line in order to achieve integration of themes and categories (p. 119). I followed this procedure and generated a story Iine that 
reflected what $I$ saw and felt was evident in the data: the strength of the students' spirit was a concept that was undeniably at the core of everything that I examined in the data. I believe the idea of spirit completely encompassed the phenomena I was investigating and became the basis of theory that this work generated. As I began to write and reflect on the emergent theory of the students' spirit, I often referred to my data analysis, and made adjustments in order to make a more cogent final analysis.

\section{$\underline{\text { Summary }}$}

The goal of the qualitative research used in this study was to understand and learn directly from the students about their life experiences and how these experiences are connected to their success in higher education. In individual and group interviews the students were able to explore areas and ideas about themselves related to their resiliency and success in higher education. In investigating the experiences of the students in this study, I was able to learn directly from them about their sense of resiliency and self-efficacy.

To ensure the reliability and validity of this research, I used several methods designed by Lincoln and Guba (1985) for qualitative researchers. I conducted a series of two individual interviews, developed a preliminary analysis of each interview and convened a group interview, 
so the students were given several opportunities to provide additional feedback. Use of these methods established credibility, transferability and dependability for the project.

In utilizing the principles of grounded theory methodology, I worked with the students to develop a theory that was based primarily on their input. The theory that emerged has relevance for those in higher education who seek to improve educational opportunities for African American students. 
CHAPTER IV

EINDINGS

\section{Introduction}

These students' expressions of resiliency are supported by various writings in the literature on resilient children and adults. Thus this study supports recent resiliency research which points to an increasing awareness that individuals growing up in stressful environments often develop an increased sense of personal proficiency in many areas of their lives. (Wolin, 1994; Werner \& Smith, 1992). The students in this study are resilient inasmuch as they have all had to overcome various stressful life experiences before they entered the university or college environment. In this segment, I document the manifestations of resiliency and how these manifestations relate to the research in this area.

In the second part of the chapter, I discuss experiences that shape the students' perceptions of selfefficacy. In this part, I offer evidence that the African American students in this study remain challenged by their own perceptions of how they believe others view them as well as the reality of their experiences and interactions with 
others and how this may affect their sense of self-efficacy. I propose that the students' source of resiliency is selfefficacy, which is the source of spirit for them. The students point to specific experiences they have had on their campuses that reflect how they believe others view them. Since their perceptions shape their reality, students' sense of self-efficacy and thus their spirits are further challenged by their own evaluation of barriers, real and perceived, in and out of the institutions they attend.

In the final portion of Chapter Four, I describe the substantive theory that emerged from the research process. I propose that the students I interviewed come to our educational institutions with a strong spirit. This spirit may have been wounded by events in the past, but upon arrival on campus, the spirits of these young adults are hopeful that a new life is to begin. However, their spirits are continually challenged by institutional barriers and racism that often make success in college difficult.

While generalizations about all African American students cannot be made from studies of small groups of students, the theory that evolved from this study did portray the experiences of the eight students in the study. Therefore, the conclusions of this particular study about any larger population are tentative and require further expansion and study with larger groups. Although caution 
must be exercised when making generalizations, we can uncover some similarities and patterns in the lives of successful resilient African American students through research with small groups.

\section{Students' Sense of Resiliency}

\section{Courage}

Courage, the ability to conquer fear or despair, was a common characteristic of these students. Most of the students I spoke with remain hopeful and optimistic about the future for them and other African American students. As African Americans in this country they are continually challenged by others' messages and stereotypes. Expressions of courage were discovered throughout the process of analysis. Each of the students expressed courage a little differently as the characteristics of this attribute persisted throughout the interview process. Later, through the dimensional analysis of causal conditions, courage became an important theme in the development of a theory grounded in the experiences of the subjects in this study. All of the students had to deal with stereotyping and misconceptions about them, and they were often motivated by this. The students are aware that they are constantly judged by their appearance. Achievement for these students involves more than the development of skills and knowledge. Referring 
to research by Spencer and Dornbusch, Taylor (1994) agrees that "minority adolescents face the task of developing an identity in the context of a mainstream culture that views the attributes and values of minority groups as unfavorable" (p. 120). The people that came into contact with these students at their respective schools and universities expected them to look, think and behave a certain way. For some of the students ignoring discrimination or blocking it out was necessary for them to get along with their white peers, professors and others. However, all of the students agreed that dealing with discrimination and learning to cope with negative bias was a matter of survival.

The subjects of this study viewed competition as another method of handling adverse reactions from others. In many instances at school and throughout their lives they became motivated by proving to others that they could accomplish much more than what was being expected of them. In fact, some of the students found great pleasure in making others look foolish when they made assumptions about them and what they were capable of achieving. It appears that these students were highly motivated to excel by the negative stereotypes present in their educational institutions. 
Learning to "deal with it"

During the process of open coding, I noticed similarities in many of the remarks made by the students. On several occasions, students said that in order to forge ahead, they chose not to take disturbing instances to heart and to just deal with certain situations. Other instances were simply blocked out.

"Repression" is defined as a defense mechanism involving pushing unacceptable thoughts from consciousness into unconsciousness (Baron, 1995). Thus, one might say these students use repression to block out instances of prejudice, discrimination and oppression that often accompany their efforts to succeed. Perhaps repression is an over-generalization of what is occurring with these students. However, one can certainly assume that these students have all found a way to get ahead in a complex, confusing and often cruel world. One can listen to the voices of these students, and know that life for African American students (especially at predominately white institutions) is not easy. From my experiences over the last fifteen years, working at five different universities, I have seen and heard the same messages from African American students whom I have coached. It appears that African American students face far more hostile pressures in higher education than do Caucasian students. (Flemming, 1984). 
It seemed that these students had to deal with many painful and discouraging incidences just to maintain a positive attitude about their school, peers and college life. One of the students pointed out that everyone in life has to learn to block things out to a certain extent. I concur, as I realize that I have learned to block things out as a woman in the male-dominated domain of athletics. But as a member of the dominant culture, I can leave the basketball court and find comfort on almost any campus in the United States, because others around look more like me. When students explained that the messages they got from people at their respective colleges and universities was often too painful to absorb, they were acknowledging the devastating affects racism can have on the intellectual and social development of African American students.

One student said she's learned to deal with racism and rise above the ways she is often perceived by others. Perhaps as the students matured, they realized that blocking out was something that was necessary for their survival. They explained that they did not want to let other people's perceptions of who they were affect them in negative ways. Therefore, they were choosing to block things out. Another subject attempted to explain that if he doesn't block things out, he will be negatively affected by how other people treat him: 
As far as college, being African American, people act a certain way to you. You gotta pretty much block that out, too. You have to get used to blocking stuff out. or like, not really block it out -- not let it bother you. 'Cause if you take it personally, let it get to you, then it's going to slow your day down. It makes you tired and it'll start to really bother you and you really start to second guess yourself and other people. And then it will bring a whole lot of problems that you don't need.

Although this pattern emerged at some level in all of the students, I found it most prevalent in the four males that I interviewed. They provided me with several examples and stories about how the people at school perceived them. It was evident that these young men believed they had to continually suppress their feelings. The following men repeatedly spoke about how the Anglo culture views African American males:

People just start expecting me to be just like what they see on TV. I remember we went to a party, and somebody got in a fight and they thought we were doing it. And we were nowhere near it. It was two white guys. People said to us "What are you guys starting trouble for?"

A lot of people wouldn't even talk to you because they automatically assume that you're some gang member that wants to go out there and beat people up or something.

The other two male students told of how they contend with difficult situations. Here they explain how they cope when they are confronted by people who make assumptions about them:

I have been pulled over three times since I have been back to school. Three times! I didn't get a ticket any 
of the three times. We didn't have seatbelts on. I have been pulled over on campus too. When he got to the car, he saw that he helped me before. So he let it go because he gave my car a jump once. But, you know, I had three African American friends with me, and I guess we seemed out of place. I don't let it bother me, though I know it's always in the back of my mind. I'm not one to say anything and get myself in trouble. Just keep my mouth shut, which I think is bad on my part. I need to open my mouth a little more.

I tend to block a lot of things out. Like when somebody says something to me that I really don't like. Most of the time, I just block it out. Act like it was never said. Act like it never happened.

In contrast to the male students, the females appeared more able to hear the messages and decipher them quickly enough to realize that the messages were stereotypes that did not apply to them. A sentiment expressed by some of the students was "I can't take things to heart."

If I run into a problem -- what the teacher is saying on a racial level, I don't think I'm going to take it to heart. Because if I take it to heart, it's going to affect me bad. So I try not to let it get to that level, and try to deal with it. Because if every time something came at me and I let it affect me, I think I would be crazy.

I'm not the only one in class here. [She was the only African American in many of her classes in high school] And I feel a little better. You just feel like you're a rat in a cage, you know; it's nerve-racking. Here, if I do run into some kind of a problem like that, I try to block it out because I know I'm here to do work and try to do good in the course and to move on. I don't let it bother me now. I think I've grown to be able to deal with it.

During her second interview, I asked this student about her previous comment and she responded by contradicting her initial statement: 
I think it's better to deal with something than to try to block it out. If you try to block it out, it's going to come back at you full force, and you're going to have to deal with it in a worse way.

Two of the other female students agreed with this student when I began a discussion during the group interview. They insisted that if you block things out, you are holding things in and keeping a part of yourself suppressed. Two students mentioned that as African Americans they sometimes have to put up a front or put on a mask. A debate ensued and another student said that it was not acceptable to put on a happy face even when one is upset. Later in the group interview this same student spoke up again about this issue:

One teacher told me it starts with you. Once you refuse to accept it, buy into it and feed off of it, it will stop. And I think that includes addressing racism head on instead of just blocking it out, letting it go or putting on a mask. It starts with yourself.

The students came to an agreement that they needed to find a balance between being confrontational and stepping back to analyze situations before they reacted.

I conclude that all of the students had to find a way to deal with racism and the perceptions of those around them in order to be successful in college. How they dealt with this differed. For some, ignoring or blocking out incidences was how they handled it. Other students chose to confront the racism in their own minds, process it and then let it go. Despite their disagreements with this and the 
unwillingness of a few to accept that they might also block things out, many of their responses throughout the individual interviews indicated that they all have learned how to deal with insidious messages disseminated by the dominant culture.

Proving to others

The students were often motivated to succeed by the idea of proving others wrong. This particular phenomenon has appeared in other studies of resilient children (Pines, 1979; Garmezy, 1976). Gorden and Song (1994) note that while this aspect of resilience has not been completely explained, it is clear that "disadvantagement is not consistently associated with negative effort or outcomes. In many instances, misfortune, rejection, discrimination, deprivation, and racism are responded to as challenges to defy the implicit negative prediction" (p. 38). There was a wide range of responses that support this theory and which led me to this conclusion.

When students were confronted with people who did not believe in them, they were motivated to show them that they could master the skill, do the work or accomplish the task in question. There was an immediate increase in the motivational level of students who were challenged by someone who did not believe in them. 
There was a consensus among the group that some people expected them to fail, and it was this feeling that motivated them to become more competitive, surprise people or do the opposite of what they believed was expected of them. Some of the students wanted to prove to themselves as well as to others that they could achieve a goal. It is interesting to note that the few students who wanted to prove to themselves and others seemed to be given more positive reinforcements in their homes as they grew up than the other students. These students seemed less likely to separate proving to others from proving to themselves. When they spoke these two statements went hand in hand:

In some ways I think I am trying to prove something, not just to myself but to everyone. And I think that I can do a lot of things with my life. So I think that motivates me a lot to go beyond what people think. I think that the standards for me or the expectations for me were so low, I think I did kind of try to prove something.

I feel like I need to prove to myself and to others. And so therefore, I can't prove myself by being a follower. I need to prove myself to be a leader.

In many instances, the students felt they had to prove something to family members, peers and teachers who questioned their potential to pursue an education:

In a way I guess I'm trying to prove something, you know? To everyone and to myself too, that I can be somebody. I can get good grades and I can get accepted into a good school.

And I'm also the type that kind of likes to surprise people and defy all odds. So if somebody expects me to 
do a certain thing, I'Il just do the opposite, just because I know they expected it. I guess I like the shock value and stuff. I like to outsmart people when they think they know it all.

Well, for me, when people told me: okay, you're not going to do this and you're not going to do that, that just made me want to show them different. To prove them different. And that's just how it was for me.

In other instances they were confronted with societal expectations and negative stereotypes embedded in our culture. This student took a risk to prove to others that they were wrong about him:

And then they were sitting there and making jokes about how Black people can't swim that well, and you're probably going to drown when you get to the middle. And it got built up and I thought: I'm going to swim there and $I^{\prime} m$ going to swim back and then $I^{\prime} m$ going to sit there and look at these people and make them feel kind of funny after $I$ do it.

Some of the students talked about the role that competition played in their lives. Two are athletes who believed that competition was a healthy way for them to accomplish tasks on and off the playing field. The other students felt learning to be more competitive would be beneficial to them as they strive to be successful in life and school:

I'm learning to be more competitive. I'm trying to learn to be more competitive in school and in my life, and I think that's important.

I asked the following student what it was that motivates him to go beyond what others expected of him and he responded: 
Just so I can prove them wrong! Maybe 'cause that's my attitude toward everything: I'm going to make you look bad, you know, for downplaying me. And just the challenge. I love competition.

While competition and proving others wrong can provide people with a great deal of motivation, it also gives one's individual power over to others, possibly contributing to the weakening of one's self concept. In competition there is always an us versus them mentality. By seeking to prove to others rather than themselves, students may be subconsciously accepting the societal messages which they are working laboriously to change. These students are continually burdened with the daunting task of proving to others versus proving to themselves that they are bright and capable of succeeding.

Insight

Wolin (1993) describes insight in resilient people as having the ability to know or sense that one's life is strange and understanding the implications of this knowledge. Knowing that strength can emerge from adversity, resilient people are able to manage and learn from experiences that often cause them great pain and hardship. The previous section described how students coped with racism and negative expectations. As resilient students, they are able to overcome many difficult life situations. 
The students I interviewed are very aware of the world in which they live. Having this insight helps them to understand the seriousness of the choices they make. It also provides them with the motivation to set goals and maintain high aspirations. These students learned a great deal from their past and more importantly they believe they can influence their future. They hold firmly to their goals. They are aware of the consequences of making poor choices and the gratification they receive from making favorable ones.

Resilient people are able to overcome great hardships. However, many received inadequate mentoring growing up and often they do not have the skills or attributes to make positive choices. "During adolescence, individuals are required to make choices based on consideration of both their own values and opinions and the optimal alternatives in a given situation. Those adolescents who are uncertain about their views, and unwilling or unable to make informed choices, are at a decided disadvantage in managing this developmental task" (Taylor, 1994, p. 120).

Many students growing up in stressful environments risk failing to meet the challenges to become active members of society (Garmezy, 1991). However, an increasing number of students from hostile environments have proven that they bring with them specific skills that can contribute to their 
educational successes (Benard, 1993; Freiberg, 1994). The students in this study have been able to overcome life circumstances yet continue to rely on these experiences to make positive choices, accomplish goals and help others.

\section{Making Choices}

Each subject in this study was acutely aware that the choices they made directly affected their success in the future. The students accepted responsibility for their actions and the consequences of their mistakes. They believe that they are able to manage their lives and influence their environment. This quality indicates a strong internal locus of control wherein students view themselves as responsible for their own behaviors versus blaming others for the outcome of events in their lives (Werner \& Smith, 1992; Graham, 1989; Brendtro, Brokenleg, \& Van Bockern, 1990). Making beneficial choices was an important lesson that all of the students learned through personal experience. One student was previously involved in a gang. He had been incarcerated and was still on probation when the interview took place. He feels that he was responsible for the poor choices he made in the past, and he places great importance on making good decisions now that he is in college:

No matter what, either way it was my choice: am I going to do it or not? So I had that decision over my life. So right now, I feel I have control over my life because I can still make the decision whether I want to stay out and be productive, and be a member of society or if I want to go back. 
I found the students in this study to be very clear about how they perceived their own roles in determining the direction of their life. On many occasions throughout the interview process, the students told me they didn't want to use their life experiences as an excuse to fail. They are independent thinkers who view the choices they make as instrumental to their success in the future:

Everything in life is either -- you can take it for good or you take it for, you know, what it's worth. You have an option to go forward or you have an option to be stuck or you have an option to go backwards. It's whatever you choose.

Your environment can keep you from succeeding, but it would be, like, a personal choice. Everything in life affects you. So I don't think people should make excuses for themselves.

Some of the students saw the choices that their mothers or fathers made and considered the poor outcomes as less than desirable. In these instances, the students felt breaking away from their families was essentially their only choice for a more productive future:

It's really not my friends that are holding me back; usually it's my family. Both of my brothers, like one's in juvenile hall, my dad's in jail. And this is just a re-occurring cycle -- what they see at home is how they act. Growing up, I was my own leader and my own parent and stuff like that. I just had to get around that and go off on my own and do my own thing.

I figured there had to be something more than what I was going through or how I grew up. I've seen lots of violence that was in the home, in addition to the violence that was in the streets. And I just didn't 
want to be a part of that. I mean, I saw all the drugs that my mother was on and I saw all the drug-addicted people that she used to hang out with, and just all that -- that kind of pushed me away.

Some researchers believe that the ability to separate oneself from a dysfunctional family environment is a major characteristic in resilient children (Benard, 1991). Maintaining a sense of their own identity along with an ability to act independently in spite of circumstances appeared to be consistent among these students. What is interesting to note, however, is that two of the students who grew up with strong family role models in the home felt they did not experience independence until they were much older. Yet both of them shared with me choices they made in adolescence where it appeared they displayed significant levels of independence.

In response to a question about succumbing to peer pressure, this student told me his parents played a part in his ability to make advantageous choices, along with his own knowledge that he simply felt he did not want to be like everyone else:

I'm different. I don't want to be just like, okay, let me do this because everybody wants to. Also, my mom, my stepdad and my father always taught me pretty good. Actually, I saw my uncle smoke weed before when I was a kid. I just said I would never do it. People make it out to be something it really isn't. And so I said I'm never going to fall into that bind and smoke weed. And so I never have. I just never fell into that. 
Displaying an incredible amount of independence, another student explains why and how she went against her parents' wishes and enrolled in another high school on her own:

I kind of did it in a sneaky way. [laughs] I went ahead and got myself into school myself. That's how I did it. I said I got basically tired of the kind of environment that was going on, [in the school she attended at the time] 'cause you would never know what was going on. So I needed a change. I filled out the information and I decided on my own. And then it was kind of a little bit too late, once we were in the counseling office, for my parents to really say anything.

\section{Having a purpose}

Resilient students who have a sense of purpose generally have goals, educational aspirations, hopefulness, and a sense of confidence that one's environment can be anticipated and that things will work out as well as can be expected. (Werner \& Smith 198; Benard, 1993). The students in this study set clear and attainable goals for their futures. They are motivated by the confidence that they can achieve their goals and a hope that their futures will be prosperous. For most of the students this means financial security, versus wealth. For others, success was the hope that they could care for their families and be secure in the knowledge that their children would grow up in loving and supportive environments.

The students also believed in helping other people who may have had to face similar life experiences. Their independence and strength appeared here again, as most of 
the students had the insight that taking care of themselves now and getting an education would help them in the future to acquire the resources necessary to assist others.

Educational goals

All of the students were driven by the belief that school success was important to future happiness. Getting an education is the assurance that they will realize the goals toward which they aspire. In their research, McMillian and Reed (1994) found that "for some students a particularly difficult experience, either direct or vicarious, reinforces the importance of getting an education" (p. 138). This is especially poignant for the following two students in this study who broke away from their families because intuitively they knew that life was not supposed to be that painful:

I want to be where I can be comfortable and my family could be comfortable and my kids could go to school and not worry about things. And I don't have to worry about things and my wife doesn't have to worry about things. That's what motivates me. Accomplish more and more before I die because, well, I don't want to have to struggle in life like I did growing up. I feel like when I get to that point where -- not that I'm super rich; I don't think that's all that important -- where I can just feel secure and have my family around.

I don't really ever remember liking school, ever. But I always knew that I had to go through it, if I didn't want my kids to grow up the way I grew up. I knew that school and an education was the only way that I could get out of it. 


\section{Helping Others}

All of the students I spoke with had a strong commitment to helping others in the African American community. It was generally the male students who expressed a strong desire to take care of their families. All four of the males that I interviewed mentioned at least once that they wanted to take care of their parents, brothers, sisters or grandparents. They also acknowledged that getting an education was important to them because they would have the resources necessary to one day go back and help their families:

I know that I can't take care of anybody else if I can't take care of myself. So, in order for me to help my family out, I have to succeed first. And then I can go back and help them out. I see myself going back and helping my family out a lot.

I keep striving. I have to be able to provide for myself, my sister and my family. I always wanted to be the one that does it. When I get older, to be the one who takes care of the family and my grandparents.

Helping others or giving back to the community served as a motivation for all of the students. This next student's statement shows that he senses there is value in his experiences that will help him when he becomes a teacher of other urban students:

I want to teach, basically, where I went to school at, so there will be a lot of the people with the same upbringing as I had. So I'Il be able to relate to them, as opposed to somebody -- like, someone I graduated with, a white student that had it good all through life. And suppose they go teach in the inner-city. I 
already have something more to offer to them, just because I had the same upbringing. And I just want to make it fun for them and make it a big learning experience, not only in the subject I may be teaching, but in life. So, basically, change the world, but one step at a time. One student at a time.

Most of the students were involved in helping relationships already. They worked as mentors or representatives in different school organizations and also off campus. This student currently works with young girls whose experiences are similar to some she had when she was younger:

With my life experiences I guess I can teach people who are coming up in the same environment how not to go left. That's kind of what I do now, with my other job. I'm kind of a counselor, big sister, mentor at a group home. It's for girls between the ages of twelve and seventeen who've been through similar things, and worse sometimes.

Many of the students appeared to spend a lot of time talking with others about the importance of getting an education.

This student shares a sentiment that was expressed by several of the others:

I know on my campus, I've helped so many people. And they know I've helped them and they've acknowledged it and everything. But to me, being able to go to college, I'm able to motivate other people to go to college. I've motivated so many people that didn't plan on doing anything with their life, to go to college.

Trust

Trusting oneself

In his research regarding protective factors in resilient children, Michael Rutter (1987) describes 
protection as the ways in which people deal with life changes and what they do about their stressful or disadvantageous life circumstances. Self-efficacy is regarded as one of several protective factors present in resilient children. (Rutter, 1987; Garmezy, 1991; Winfield, 1991; MCMillan \& Reed, 1994; Werner \& Smith, 1992). The data analysis revealed that the eight students I interviewed were notably cognizant of their own ability to succeed far beyond what others may have expected of them. The protective factor of self-efficacy was evident in the students that I interviewed and this theme is supported in the literature on resilient people. The students' responses suggest they believe in themselves and their ability to succeed. They further believe that they have been successful partially because they are smarter in adapting than others with whom they had been associated. The comments made by the students indicate that they adapt well and believe in themselves and their ability to achieve, despite the disabling circumstances they have encountered.

Among the responses, various levels of consciousness became apparent. Students understood how experiences shaped their view of themselves and belief in their ability to succeed. The term smart was consistently used by all of the students. This term was used by the students in several contexts. Smart referred to intellectual abilities as well 
as self-confidence based upon their past experiences. The students were smart enough to know that they are capable of accomplishing a great deal despite what others tell them. Smart becomes a process of thinking, feeling and acting. Their actions are generally based on an awareness developed through past experiences:

And by me having all the experiences that I've had, it just lets me know that in spite of anything I'm still smart, I am still clever, I am still -- you know, all these things. And they do help me succeed in college.

What made me feel I could do better is that my mom and dad had so much talent, you know, they put it to waste, basically. And so I know I had something special to offer to everybody.

Two students seemed reticent about expressing views of themselves as smarter than some of the other people that they knew. They believed they were smart intellectually, but it appears they were also smart in interpreting their feelings and actions which were based on their life experiences. Both students who made these statements had severed relations with extremely dysfunctional families:

It's just the way my parents were. How they were just not there, and my brothers, followed in their footsteps. I had to show that good example, like -somebody from our neighborhood can make it, you know? Can go out there and do something. And I wanted more than what everybody wanted to do. So I guess just everybody -- was on a -- they were kind of mediocre; I felt like I was a little bit more than that. So I guess I was striving to be better than everybody else in something.

I don't want to put myself above anything, but, I mean, I'm just smart. I mean, I know what I want to do and I know what I don't want to do, and I know that if I do 
certain things that my goals will be just stopped or put on hold or just -- they won't come true, or whatever. And that's just how it is.

The awareness that the students had concerning their ability to do well in school and in life often provided them with the strength to resist peer pressure. In the previous two illustrations this confidence in their ability to be academically successful kept them from conforming to the lifestyles of their friends and families. The student above who talked about the possibility of not achieving her goals continued:

That's why I never succumb to peer pressure or anything like that. I always knew that I didn't want to do any of that stuff that would take me off course.

The students demonstrated trust in themselves and displayed confidence in their abilities. This was based on the strength and insight gained from successfully overcoming difficult life circumstances. However, their confidence can be shaken by further challenges in the college environment. One student frankly stated, "The college system is not going to always validate that you're this awesome human being." With this in mind, African American students must maintain their sense of self and find encouragement from others whenever possible. 


\section{Trusting others}

Every student involved in this study had the ability to trust on some level. I am grateful for their trust in me as they allowed me to ask questions, some of which were of a personal nature. From the outset, some of the students seemed to trust easier than others. Initially, there was a hesitancy in some of their responses and an apparent mistrust of me and my intrusion in their lives. This sense that I had was clearly my perception, and the fact that these students took the time to spend several hours talking with me is a testament to their willingness to take a risk and trust me and the integrity of my intentions. The foundation of their trust was generally built upon the understanding that the information derived from this study could help others.

Researchers have concluded that another protective factor attributed to resilient students is the availability of supportive adults who foster trust, encouragement and a sense of coherence or faith in the lives of young people (Werner \& Smith, 1992; McMillian \& Reed, 1994). The data revealed that these were consistent factors for the urban African American students in this study.

Each of the students mentioned an adult who made a difference in the way that they viewed life. For some, it 
was one or both of their parents who made an impact that

fostered trust:

I feel like this: I couldn't come home with anything lower than a "c". Because my father, he was military. And it was like, he was always on my back! And I would hate his guts. And I never understood it until now.

I have a stepfather and a real father. So I have two different father figures and parents, as well as all kinds of adults that tell me different ways and different places and just explain how different things are.

For others, it was part of the extended family who provided encouragement that cultivated trust:

My grandfather always made me read, he always made me do math, he always had me in educational things. So now that I am older, I remember that this is the route to go. Even though it was only for a short time, I still remember him.

I think I owe everything to my grandmother. She would always sit me down and tell me I want you to make it. I don't want to have to go through all of this again when you grow up. So I took it upon myself to be a good person.

For others it was someone in the system, a social worker or teacher that encouraged the students and helped to foster trust:

I can remember one person [who helped her]. Her name was Betty and she was my independent living skills social worker because I grew up in the system. And she referred me to EOP.

When I was incarcerated, my counselor was a big part of it because she was the only person that I had explained my feelings to. She knew how I felt and she would always encourage me. And she would keep pushing me no matter if she saw me slacking or something, she would push me harder. 
Certain teachers and my counselor stuck with me for four years. And to this day I still keep in touch.

Without exception, the students gave credit to someone for influencing their thinking and supporting them when they most needed it.

One student lived with his friends and their families because he did not get support from his own family. His ability to trust enriched his experience and his future:

Basically I stayed with my friends since the sixth grade. I stayed with this friend and that one and they would help me out when I needed help and I guess I saw their families pushing them to succeed and so they would do the same for me, their parents. 'Cause they knew my family situation. They would tell me "you gotta do this also." So they were more like my father and mother figure than my actual parents were. They knew I wasn't gonna amount to nothin' if I stayed there. I'm super grateful for that.

\section{Students Perceptions of Self-Efficacy}

Experiences shaping perceptions

To understand someone else's reality, one must describe reality from the other's point of view. In grounded theory methodology, participant input is essential. In my search to develop a theory that was grounded in the experiences of the eight students that I interviewed, knowing their reality became a quintessential qualitative component.

We see things not always as they are, but as we are. Since we see the world through our own experiences, our 
experiences are constantly shaping our perceptions.

Moreover, our perceptions are our own realities. One cannot dismiss others' perceptions of reality, nor should we assume others perceptions are always similar to ours. Even though the perceptions of these students are often in contrast with the perceptions of the Anglo culture, they must not be ignored. In fact, they ought to be validated.

"People tend to act on the basis of how they believe other people behave toward them; and their self perceptions and feelings tend to be mediated by how they think others see and feel about them" (Van Manen, 1990, p. 186). Along with the stresses present for every student in the context of higher education, African American students face additional pressures of being perceived as less capable than their White peers. Being valued as significant, productive and capable is important to all students including those who are African American. Claude Steele (1992) believes that "society is conditioned to see the worst" in African American students. He further notes that "Black students quickly learn that acceptance, if it is won at all, will be hard-won" (p. 74). The responses from the students in this study support this statement as they describe their perceptions of how others in the college environment regard them. 
The students spoke of how they believe other people view them and occasionally how others treat them. They are often frustrated with the knowledge that for them, getting an education requires much more than studying hard and getting good grades. For them, academic success requires prevailing over the ignorance and perceptions of the dominant culture. All this must be accomplished in educational settings where institutional racism appears to remain widespread.

The following student talked about how he felt at the predominately white institution that he attended. He mentions that people make statements that do not really reflect who he is. He doesn't understand why people at his school don't see that he has something positive to offer. He thinks that people use specific statements because they do not want African American students at his school:

I'm just here to meet a quota. I have heard that. Why? The way I see it is why don't they think I have anything to offer [school]? Why? Why, just because I am Black? Why can't you just be satisfied that I am here and you know me? And leave it at that?

As previously mentioned in part one of this chapter, all of the males I interviewed expressed feelings about the perceptions of the dominant culture in regards to African American males. They often expressed anger, sadness and frustration when discussing how others viewed them. They hoped that people in college would judge them after they got 
to know them, not before. Unfortunately, they believed many people would never try to befriend them because they were perceived to be a certain way:

People expect I'm going to be violent or aggressive. I mean, I don't walk around angry all the time. I'm not a thief. I'm not what people might think. The only reason they think that we're like that way is because of what they see on TV and stuff like that.

A lot of people get intimidated or something when they know where you're from, and they are reluctant to talk to you or hang out with you, because well, first of all, you're Black and then you come from a bad neighborhood. And people are like "Oh, I don't want to hang out with this guy. Might be some criminal or something". Basically, in college, that's the only thing that really holds you back.

Some students who are also athletes feel that professors and students make judgments about them and their ability to excel in the classroom. I have heard the following comment from African American men and women in several colleges I have worked at. The following student was an athlete, but he was not on an athletic scholarship. He desperately wants others to know that he is much more than just an athlete:

[People think] I'm just another jock here on scholarship. I'm going to school for free cause I can play football. But you know, [subjects name] goes deeper than that, so that's the way I see it.

Adapting to Racially Hostile Environments

Research studies indicate there are certain variables that contribute to the success or failure of African 
American college students. Among them are the perceived supportiveness of the environment, feelings of alienation, and the effect of adaptation strategies used to cope with pressures (Prillerman, 1989). These students often felt they were not accepted by others at the colleges and universities they attended.

When they were faced with these feelings, each of them displayed internal mechanisms for managing their emotions. Usually, as the previous data reported, they chose to just block it out or deal with it. All of these students were adept at handling many challenges because they possessed the insight that they would learn from and become successful despite, the attitudes and perceptions of their peers, professors and fellow students.

Only two of the students gave me specific examples of situations where professors were blatantly racist towards them. In both of these instances, the students were speaking about experiences from high school. On the other hand, all of the students talked about having a feeling that a professor was treating them differently because they were Black. Sometimes the students talked about getting too much attention because they were the only African American in class. Most of the students shared feelings of frustration and disappointment in their perceptions of how white 
professors, classmates or university personnel seem to treat

them because they are African American:

One of the things that frustrates me is some of my White professors, they kind of treat the Black students very unfairly. They tend to stereotype us, pre-judge us before the class even starts. I mean, it's just, you can tell, the way they sometimes pass over us, or the way they -- if you ask a question, they might answer it in a way that would make you think that they think that you are intellectually inferior or just incapable of understanding exactly what they're saying.

Sometimes I am kind of slow at learning things because, I go back to that, you know: "Oh, I can't do it". That type of thing. And paranoia, mainly; it's like: "Oh, they're going to think I'm stupid because I'm Black". Sometimes I actually think that. And I try not to let that hinder me.

Many of the students mentioned that people perceive them as

less than capable. The following two students suggest how

they handle knowing that others view them as incapable:

It's just the whole way that I think people look at us. I don't think they think we should be here. We should probably be on a street corner somewhere. I think that's what they want to think. But I try not to worry about what other people think. I mean, I'm here. And $I^{\prime} m$ not going anywhere. So that's it.

Even though my White friends are -- I'm pretty sure half of them think they're better than me. But I look past that, you know? 'Cause I may be thinking the same thing about them. 'Cause I think myself, I'm a good person; that's what makes me better than them.

\section{Working Harder and Acting Better}

When asked about the differences and similarities

between them and their classmates, the students had a variety of responses. Some of the students said there was no 
difference. They believed they were all there to learn and they all had life issues to deal with. During the analysis, I noticed that this particular response came from those students who did not attend predominately white schools. The following sentiment was offered by a student who had attended institutions that were predominately white. Many of the students stated they had to work harder than the White students they went to school with. This insight was based on their own perceptions of how others viewed them:

Nobody knows how it feels to be that one race except you. And I found that my first couple years I found that very intimidating. Especially being in that class, being the only race, you find yourself having to put more effort into your work and try to get over that.

About half of the students agreed that all students work just as hard as they do. But those students indicated that there may be other barriers for them to contend with that could affect their classroom achievement:

I know they [White students] have to work just as hard in the classroom as I do to get their grades. It might help them that they don't have other things to worry about, like is dad going to be all right, is dad coming home, things like that. So they don't have to fear for anything.

Not only did the students feel like they had to work harder, they often stated that they had to constantly be aware of their actions in and out of the classroom. This next student had the insight that people tend to judge his intelligence by his actions and behaviors. However, he was keenly aware 
that he was capable of future success because he believed this insight gave him a distinct advantage over other less aware White students.

It's hard because I feel that if I was to do anything stupid, it would be like stereotypical: "I knew that would happen," or something like that. That is why I take it upon myself not to do that, and be looked upon as, up there as one of the better students. I mean, not as far as in the classroom, but as a person. Because I know some real iuad people. Some white guys here are real bad, but they are still great in the classroom. I wouldn't say I was so great in the classroom, but I know I am a better person altogether."

\section{Being the only African American in Class}

Eour of the students I interviewed were not attending predominately White institutions, and they did not respond in the same ways as the other four students during discussions about being one of a very few number of African American students on campus. However, one of those four students did have similar feelings from high school where she was the only African American student in many of her classes.

Nearly all of the students had experienced being the only African American student in a class and several expressed how difficult that was:

I took a physics class last semester and I was the only Black person in the class. So I looked around, like, man, I'm the only Black person here! I don't mean to do it, but I see myself doing it sometimes. And I'm trying to get out of that because once I get to the upper level, with the classes that I want to take, there might not be any African Americans in the class. so I'm trying to get out of that way of thinking. 
It's, like, you're in a class of maybe thirty-five, forty people, and then you have only one Black student, you know? Where is all the collective work? Where is everything?

If $I^{\prime} m$ reading a book in my South African class, my teacher, I mean she's a nice lady, but everybody in class looks at me every time she says anything about African Americans... I'm learning just like they are. The teacher, she is teaching me. 'I'm not teaching the class. So you can't look at me for answers. You're supposed to teach me what I'm supposed to Iearn to get an " $A$ " in this class. There's people that expect me to get upset if the teacher says something about apartheid or this and that or expect me to raise my hand. And if I raise my hand, I can say something totally ludicrous and people will still agree with it just because they think that I'm supposed to automatically know.

I asked the following student how I would feel and what I would see if I were looking out from his eyes his first week of school, and he responded:

Everybody has been stereotyped. If you were to look into my eyes, that's what you would say. I mean the only thing is, where is anybody like me at [this school]? You know, that is how you would basically feel, out of place at first.

This same student continued his response and shared with me how he relied on his life experiences when searching for ways to find comfort in this environment. He believes he has learned favorable ways of adjusting, whereas some of his African American friends have not:

But as far as myself, I would make friends, as many friends as possible. Growing up where I did, I got bussed to a rich neighborhood again. It is sort of the same thing that I did here. I look past all of the racial things 'cause by no means do I have anything against any race or anybody. I settled in fine. Some people wouldn't, like some of my friends. 


\section{Feeling the Pressure of One's Appearance}

As I have said before, the males I interviewed appeared to have concerns that were unique to their gender. Here again, the males addressed the issue of people's perceptions. However, in these instances, they felt strongly that their physical appearance could shape the way white people view them:

I am not trying to fool anybody, if they ask me I'll tell them my family has no money. But I am still going to try carry myself well. I'm not going to carry myself like I am poor because then people are going to look at me in different ways: "Oh, he is just another poor Black person here on financial aid."

You don't want to come to school looking like a thug, to what they would make you. If you're going to come to school, at least be presentable. At least look nice to where they can't affiliate your clothing. People are still going to think that anyway. They are still going to stereotype you and jump to conclusions. But don't really give them that excuse to do that. So when I come to school I look the best I can.

I really feel that they're lother African American students] setting a bad example for what Black people are supposed to be like. I guess the hard thing about it is, it's not really what people are doing to us, it's what we really portray to other people. Usually when I come to school I am dressed nice. I'm in student government so I have a high role with the faculty and stuff like that. And a lot of people say I am kinda stuck up. But that's not what I portrayed. I just want people to believe that we're not this low-class people that are lazy and don't do anything.

\section{Relating to African American Students}

Every student talked about people in the college environment relating to them. Some of the students were more able than others to verbalize how it felt when others did 
relate to them. They spoke often about the relationship between them and their professors. The students expressed a desire to be treated just like everyone else in the classroom. Most of them had come to the conclusion that this was not possible. All of the students, had at one time or another, a professor with whom they could relate. It was during these periods when the students said they learned the most and felt valued in the classroom.

Appreciating the Professor and Student Relationship

When asked directly, some of the students said that the professors did not need to know anything about them or their background. However, those same students later mentioned the types of professors they thought were most effective and those they were most comfortable with. In nearly every instance, the students described professors who spent time getting to know the students, who made themselves available to students and who appeared as though they really cared. The students believed having positive relationships with professors was beneficial and aided in their own motivation and learning:

Some of my professors, they make a lot of eye contact and they do a lot of stuff to kind of affirm your presence in the classroom; well, my Black teachers do a lot of that. They do a lot of eye contact, they smile a lot and they talk to you a lot after class and they interact with you a whole lot as if you were part of the family, like they really care. Sometimes that makes a big difference in class. 
If you go in there and talk to him about Algebra and about yourself at the same time, how you feel about that class, not just, how you do this problem; can you show me; I'm a little confused. But if you also go in there and tell him how you feel about that class, how it contributes to your outside life, then he can learn more about you because he can see: "okay, well he's this kind of person". Because perception is life. At least he will be closer to perceiving you as to the way you are than he will be without you doing that.

I know that when that happens [when the professor gets to know the students betterl, the student/teacher relationship is a lot better. My English teacher really got to know us. And you knew you couldn't get over on him, so you've got to do something 'cause he's going to put you to the test all the time, because he knows what kind of person you are. And if you come in one day and you're feeling down, he knows what gets you going.

In the students' view, the ideal professor / student relationship is forged when the professors can relate to the students. Some of the students thought that African American professors could relate to them better than white professors could. Other students believed that race was not as important if the professors could find ways to understand all students, regardless of race:

I think that if teachers could just relate to students. They don't have to have your life experience, but just relate on a certain level. I mean, not making a student feel like they're stupid because they ask a question that might not sound inteligent, you know? In their eyes, it might sound intelligent.

I guess they [professors] could give us a little bit more understanding about certain stuff. Not special attention, but just understanding. Like, it's different here, you know? We are three percent of about ninety percent of the different colors on the campus. After a while it takes its toll, and sometimes you just try to second guess and start to feel certain ways. 
It was difficult for many of the students to verbalize how they thought professors should respond. I suspect that it is a feeling that is difficult to express. The experiences they have with many of their professors are neither negative nor positive. It is often a feeling, a nonverbal communication that expresses to one the essence of who they truly are. The professors may not commit racist acts, or make disparaging remarks. But it is the human connection between two people that has a direct effect on the students, spirit.

I believe this young man understood the connection:

If you're going to be an understanding teacher to African Americans, be understanding out in public. I don't really know the words I'm looking for. Just kind of live your life and try to live your life the way you would teach it. The way you would teach it in class. Don't just be extra nice to African Americans just because he is African American. Just be aware of everybody else's culture. Just don't be stuck in yours.

He may sound as if he was telling me how professors should be. But to capture the essence of what he is saying, one must look beyond the spoken words. If professors really want to understand all of their students, then for some this is a Iife change. For some, this means embracing difference as you do your own spirit. Accepting difference as a part of who you are as you live your life every day. As educators, we cannot be told to relate to all students. We must have the desire to understand and the willingness to open our hearts to learn from others who may look, live and act differently than we do. 


\section{Not expecting special privileges}

At one point or another, every student that I spoke with said they did not want to be treated any differently than any of the other students in the classroom. They did not want to be treated unfairly and they did not want any special privileges because of their race. In this respect, they are probably no different from the majority students in the classroom. They expressed their desire to engage in the learning process like all of the other students in the classroom. However, they realized that people are not color-blind, and they would like the professors to acknowledge the difficulties that race causes. Yet they would prefer to be treated like everyone else.

[professors should] Treat me like everybody else in the classroom. Just try to know what it is like being one of the few African Americans that go to this school. Just only think about it and sympathize with me, and don't treat me any differently. Just treat me like Joe, you know, don't look at me weird or do anything. I am just another student trying to get a good education, just like Joe sitting next to me. That would help my success if I didn't have to worry about a professor: Is he going to treat me differently because I'm Black? I shouldn't have to worry about that.

I don't want any special privileges because of my race. I feel I should be just taught like anybody else. Once you get into the classroom, then everybody should be seen as students.

Many of the students wanted their professors to know that they were motivated to learn. The students often saw the professors as the enemy who did not believe in them, did not 
trust that they were motivated and interested in the

learning process.

This particular student was fearful that if she talked

to the professor about getting extra help, she would be

viewed as someone who wanted an extra benefit:

Professors need to know that me and other African American students are motivated to do well. I don't expect instructors to make exceptions for, quote, unquote, minority students, but to think of everyone as an individual, not a number, and offer assistance to those who need it and who are willing to work to improve.

A significant paradox exists in the students' perceptions of professor / student relationships. The students would like to develop a rapport with the professors. However, institutional racism and the students' perceptions of racism seem to be barriers to this endeavor. For instance, if these students approach professors for help, they are fearful that they will be judged harshly and be looked at as expecting special privileges. On the other hand, if they do not develop rapport with the professors, that faculty member does not have the opportunity to understand the students' needs or background.

Learning about African American culture

One of the most important school experiences these students discussed was learning about their own culture. For some, the experience was powerful because it was the first 
time they would be in a college classroom with many other

African American students:

If I'm taking an African American culture class, it seems like I can relate more, like, on a social level with the people in those classes. I don't really feel like I can relate to a lot of the people that are in my classes now.

I asked the students what made them feel happy their first few weeks of college. Two of the students said that what made them feel happy was looking forward to learning more about their culture:

I was looking forward to taking some African studies classes, which I never had in high school. I've always wanted to find out more about me and where I came from, where our people come from, what we did and all that stuff.

I was happy that I was going to be in a Black studies class and it was fun. When you're in school for twelve years all you learn is Eurocentric history. And you don't get to learn the other side. All you see in the books is about some pilgrims. You see slaves and then you see all these things that white men have contributed.

The significance of this information is underscored by the statements of this young man, who grew up with negative feelings about his family, his race and his own sense of who he is:

As I was growing up, I know all the Black people were seen as lowlifes and we were, like, nothing and everybody else was, like, raised up and they were feeling better. And I was kind of ashamed of being Black. I was like [dismissive sound] "I could probably pass for something else, I'm kind of light-skinned." I always used to think that. But as I got older and started learning more about my culture and what we've been through, it made me proud to be Black. 


\section{Self-Efficacy as Spirit}

In utilizing the principles of grounded theory methodology, I have explored, analyzed and integrated the data to generate a theory that is grounded in the specific experiences of the eight African American students involved in this study. The emergence of spirit came from the data analysis in the advanced stages of this work. The term spirit encompasses every previous theme and seems to best describe the students I interviewed. As new ideas continued to unfold, this theme became a prominent framework for my analysis.

Spirit can be defined as a life-giving force or vivacity and enthusiasm for life. This is the quality that best represents the students in this study. All of the students dealt with various life challenges growing up, and as African Americans, they are burdened with the additional requirement of meeting the Eurocentric institutional norms of the college environment. In spite of the difficult personal and intellectual tasks that the students in this study spoke about, they appeared to maintain a sense of hope that their future and the future of their families would be productive, peaceful and healthy. They are the kind of survivors who have spirits that can be injured but not broken. In fact, in many instances their spirits are strengthened by problems surmounted in the past and present. 
This strength continues to reinforce their spirits into adul thood.

Several of the students arrived on their respective campuses with spirits that were wounded by the experiences of their past. All of the students came with a sense of hope that a new beginning was about to occur. As time passes, each student encounters challenging situations. It is during these moments that the students rely on the strengths they possess as resilient people to preserve their spirit. This can be a difficult process for young people trying to navigate in the already complex and confusing college environment. We must find ways to support, nurture and appreciate these students and the strengths that they bring with them to the academic setting. When this occurs, these students may leave the educational institutions with spirits that are strengthened by the positive experiences presented to them.

Wounded Spirit

From an early age, the spirits of these young men and women have obviously, to some extent, been wounded. As I listened to their voices, I could sense the pain, anger and frustration that they often chose not to address. They each had developed a style that aided their adaptation to various environmental circumstances. These African American students were chosen because they met additional challenges of 
growing up in stressful circumstances. More than half of the young people involved came from unstable home environments; all have been able to overcome barriers that many others apparently do not surmount. For half of these students, chaos in the home was commonplace. For the others, stable family members helped them to make sense of the outside environment that was sometimes difficult to understand. Responses indicated that each student was intuitively aware at some level that their previous life experiences contributed to their ability to succeed now as they work toward earning a college degree.

The students demonstrate their sense of resiliency in many ways. They are courageous and insightful. They have the ability to make positive choices and they maintain a sense of purpose in their lives. They believe in themselves and their ability to achieve, sometimes far beyond others' expectations. And finally, they are able to trust others who provide encouragement and support. However, these students continue to experience Iife events in college that constantly threaten to impair their sense of resiliency and impede their success.

The students I spoke with refuse to allow negative experiences to influence their commitment to succeed. This supports the view that resilient people are able to learn from and seek out positive forces in one's life, and not 
replicate the incapacitating or damaging elements of their environment (Benard, 1991; Williams, B. \& Newcomb, E., 1994; \& Sautter, C., 1996). For some of the students who had stability in their homes, life may have not been as rigorous. However, that is relative to everyone's life, and I will not judge who has been more affected. Currently, they are all challenged to meet the norms of the dominant culture and they are functioning effectively in society. Their spirits have been tempered and each of them remains tenaciously hopeful.

Hopeful Spirit

As they entered into educational settings that appeared intimidating and frightening, these eight students were hopeful that their school experiences would be positive and meaningful. As noted in the first part of this chapter, most of the students knew that getting an education was essential for a secure future. They realized that college would be difficult, but it was something that they looked forward to. The following statements were made in response to a question about their first week of school:

I was kind of excited because it just seemed like a whole new beginning.

I felt good because I was finally here! I'm on the road to being where I want to be in life. I was excited about it, finally getting my life started.

Some of the students expressed other feelings about entering the college environment. Among those who had different 
feelings was the following young man, who had some prior gang involvement. He felt pain because he was reminded of all that he had endured before he came to college:

A whole new world opened for me when I came here. And a lot of happiness. I also felt pain when I came here. I just felt pain because I was happy to be here but then when I thought about what I had to go through to get here, you know, to realize that this is where I wanted to be, it hurts.

Other students felt alienated and insecure upon arrival at college. This will be discussed in the following section. Even those students who initially felt alienated and alone, were hopeful that their school experiences would be more positive than some of their life experiences:

It's just, I don't want to be there, so this is the only alternative for me. This is the only way. So far, my school experiences have been positive and my life experiences have never been positive.

This hope that the students have is founded on the belief that getting an education is synonymous with success. Most of these students may be the first in their families to achieve such a goal. Yet, despite the obstacles and challenges they face, the students in this study continue to have hope that they will live happy and prosperous lives. Challenged Spirit

Throughout the study the students' responses indicated that they were aware that their lives were more arduous than many others attending their college or university. 
Initially, some of the students were anxious and fearful. It was difficult for these particular students to feel good about entering the university environment. The following student attends a predominately White institution. She describes how she felt out of place and alone when she arrived on campus:

When I first came here, I felt like a foreigner in a new country or something. I felt a little confused, lonely, like I didn't belong there, this particular setting, initially. The transition from high school was hard. I felt lost, like something going down the drain, in a whirlpool or something like that. People looked at me funny. I also saw a lot of White students. Didn't see too many that looked like me.

Unlike the previous student, the next young man felt very happy when he arrived on his campus, which was also predominately White. However, feelings of happiness were soon replaced with disappointment when he realized that people did not really accept him. He began to notice some of the behaviors of the people around him. He eventually realized that racism was something that he would have to endure while he was in college.

The first couple of days I felt pretty happy. I didn't feel alienated any kind of way. Everybody came to me with open arms, it seemed like. But after a while it progressed. I started to see things different ways. I mean, after a while you live with somebody for a while or live next to somebody you get to see the ways that they really are. At first, I wasn't noticing it at all because I was so joyful. 
It appears that many African American students are affected at some point and in some way by racially hostile environments. It is clear that the students who attend predominately white institutions are much more likely to experience racism on campus. But every student that I interviewed was affected by others who stereotype and judge. All of the students have learned not to succumb to the destructive verbal and nonverbal messages they receive. Although they realize that these messages are generally based on ignorance, disruption of one's self-esteem and confidence is inevitable.

Since these students have already faced many difficult circumstances, they are often able to look inward for the strength to maintain their confidence and self-esteem. In the previous portion of this chapter, perception was discussed. These students have their own perceptions of how people view them. As humans, we see the world through our own individual lenses.

Because I am a white researcher, I view the world through a lens that is constantly validated by the pictures and images that I see every day. That is the privilege of being White in America (McIntosh, 1988). African Americans do not have such a privilege. They must constantly grapple with the uncertainty of the moment during any unfavorable experience. Not only are these students challenged by the 
perceptions of others, they are also challenged by their own perceptions of how they believe others view them.

African American students come to college with the same expectations as other students. Many of the students who come from stressful environments are hopeful that taking this step will provide them with positive opportunities to learn and grow. Yet, within weeks, many of them are aware that they will be challenged another time and their spirit becomes wounded once again.

Nurtured Spirit

Some of the students did not initially believe that they could or would be successful. Even though they perceived that they were smarter and more able to adapt than many of their peers, sometimes they were shaken by old belief patterns based on past experiences. In the past, more often than not, when they arrived on campus, they were unsure of themselves and their abilities to succeed. Once they realized that college is not as complicated as it appeared, their motivational levels began to increase. These same students became more confident with each success.

One student described how his confidence was bolstered when he understood how the college system worked:

I know when I first came to school I thought everyone was smarter than me. And it turns out a lot of people are, because a lot of people went to private school. Not really smarter, but they know how to apply themselves better. Initially, you just think that you can't handle it. You can't compete with everybody here. 
Once you get here, you realize it's just something that you just didn't know about. It's unknown. But then once you figure it out and get to know what it is, then it's not as bad as it seems to be.

Another student remembered that he was not very motivated in high school and this knowledge kept him from believing in himself when he first began in college. However, he realized that if he took a risk and put forth some effort, he grew less intimidated:

At first, I felt like I didn't know if I was going to be able to make it. I was just, like, going through the motions. Because I knew the kind of student I was in high school. I was lazy and I didn't want to do anything. So, I was like, will I really learn anything? Kind of hesitant. So, I was, just worried at first. But, once I got going, it was all right.

This very same student found that he was motivated by experiencing positive feedback through good grades. When he received his first exceptional grades, he truly believed in himself and now expects he will continue to earn good grades:

I remember the first time I finished a whole semester here, I was, like: "Wow, I got good grades!" It was like something I was really proud of. And after a while you start to get into school. It's like something that's expected of you; it's like run of the mill.

Several other students related how positive educational experiences gave them the confidence and belief that they could make it in higher education. Positive educational experiences include academic achievement as well as social 
adjustment and verbal and tacit acknowledgment. The acknowledgment of the achievement, no matter how subtle, increases the student's motivation. This also has an effect on the students' expectations of themselves and influences the expectations of others.

For example, this next student's family did not even expect her to go to college. When it was obvious that she was becoming successful in her academic endeavors, the family expectations increased and in turn this became a motivating factor for her achievement:

I want to be successful and I didn't come from a successful family. Or a successful environment or whatever. That pushes me. And the fact that now I have a lot of relatives who expect me to do a lot of stuff now. Whereas before I really didn't, so that's a motivating force.

The multiple dimensions of nurturance are reflected through the family as well as the college community. Nurturing can be complex because of the contradictions present in the students' relationships on and off campus.

Nurturance takes place on campus, which spawns another contradiction. Throughout the interviews and in the transcribed documents there existed a contradiction between attitudes and feelings. A significant number of students described what appears to be a continuing paradox. An ambivalence existed in the students' expressions of their feelings about their experiences on campus. There was a 
continuous fluctuation between affirming attitudes by others versus the disheartening and negating behaviors they often experienced. The first part of this paradox was touched upon in the remarks about the numerous negative experiences these students have encountered. The second part of the paradox is described here with a few examples of the notable expressions of positive experiences and contacts students had with people on campus.

The following three statements were made by students who Iived on campus and attended private four-year schools:

Everybody at this college, no matter who, are like so courteous. Or so nice. And it sometimes makes me feel weird because I've never been around so many people like that. Everybody being so nice to me, it feels weird sometimes because I'm not used to it. But then again, it feels good too, and I return it. I give them respect, most of the time more, you know?

For the most part, a lot of people here are nice. All that I've encountered, just about. I've met a lot of people, have a lot of friends. I've gotten nothing but support.

I met so many different people also on this campus that actually helped me progress. Like, I have a lot of multi-colored friends, and they are just people. It worked out perfect, like my best friend, John. He's White and from a total opposite culture. But we both came to the same place. So stuff like that helps me grow.

The aspect of nurturance is highly important in maintaining and healing the students' spirit. They are more able to succeed when there is nurturance of their strengths as resilient people. Support for these resilient qualities comes from all segments of the college community. 
Recognition of the need to establish a nurturing environment is critical.

The students in this study revealed how they perceive their environment. Furthermore, they believe the difficult experiences they encounter make them stronger than others who do not have similar challenges. The majority of these students are hopeful and happy about being in college. However, they become disappointed and frustrated because they do not always feel the institution understands nor embraces them. They then rely on their strengths as resilient students to master the collegiate experience. The institution becomes strong when it nurtures the strengths that these students bring with them. The institution can demonstrate its support by nurturing these students and modeling acceptance. Moreover, there is a reciprocal value for the institution when it recognizes the need to provide a community for all students to learn and develop. Most importantly, professors and college personnel can model and support the numerous attributes that make a successful student. This model in the college community will not only support African American students, but all students. 


\section{Metanalysis}

The findings in this study reveal much about resiliency and the sense of self-efficacy of the eight African American students who participated. Each of these students had a story to tell about themselves, their families and their lives in school. While each story was profound and personal, there were many similarities in the ways in which the students survived, learned to overcome obstacles and push themselves to achieve.

The four major themes of courage, insight, trust and perceptions of self-efficacy represent some of the most significant and poignant ideas and descriptions the students shared with me. Even though they were challenged by past experiences, the students displayed a strong sense of selfefficacy as demonstrated by their willingness to trust; insight and ability to make positive choices, set goals and believe they have a purpose; and courage to work through even the most difficult situations.

These students demonstrated through their actions and lifestyles that they were able to overcome almost any obstacle. They proved that although life was stressful, it did not have to be immobilizing and in fact, their experiences in many instances proved to make them stronger. They displayed an incredible amount of resiliency simply by attending college given the obstacles they had to overcome 
along the way. Their sense of resiliency appeared again in discussions about their experiences on campus and in the classroom. Being resilient aided in these students' successful transition to college.

An inner strength which I refer to as spirit helped the students triumph over many of their past and present disabling life experiences. I believe the data support my premise that this inner strength or spirit is the source of the students' self-efficacy, which is the source of their resiliency. This construct of spirit emerged through the use of grounded theory methodology. Again, the purpose of grounded theory is to develop a theory based on the input from the participants in the study. Furthermore, grounded theory must be relevant to the subjects and useful to others.

As the theory of the students' spirit emerged I realized this concept encompassed every other theme in the analysis. The students in this study were both African American and resilient. Their spirits were often wounded by past experiences but they remained hopeful as they entered college. Their spirits helped them to believe in themselves and their ability to succeed despite the negative messages often sent by family members or people in the campus community. Here they are challenged further by the 
individual and institutional racism displayed at their respective institutions.

This theory of spirit may help educators understand the unique positive attributes possessed by resilient African American students. In addition, this study may encourage educators to re-examine the programs, policies and teaching practices that are currently being utilized in most colleges and universities in the United States. I discuss the implications and recommendations in chapter five, and I hope this knowledge will encourage educators to be more open to understanding, appreciating and respecting the perspectives of all marginalized students. 


\author{
CHAPTER V \\ SUMMARY, IMPLICATIONS, RECOMMENDATIONS
}

\begin{abstract}
Summary
I began this study with two research questions in mind: first, what can we learn from African American students about life qualities such as resiliency, trust and selfefficacy, and perhaps others, that may relate to success in higher education? And second, what educational theory might emerge to guide teacher and student relationships, given the grounded theory that comes from this study? The data may provide readers with insight about how we might respond to students' experiences in order to elevate their rate of success in higher education.

While the students in this study can be identified by their indomitable spirit and persistent determination to succeed, they are resilient inasmuch as they have continued to excel despite difficult and often disabling circumstances. However, "expecting all students, particularly those from subordinated communities, to be resilient in this way is an unfair burden, because privileged students do not need this quality, as the schools generally reflect their backgrounds, experiences, language,
\end{abstract}


and culture" (Nieto, 1996, p. 56). For example, White students attending college (at predominately white institutions) benefit from seeing professors, administrators and peers who look like they do; learning about history and culture from a perspective that they can relate to; and living in close proximity to other students who will readily accept them. African American students do not have this Iuxury. Therefore, I suspect resilient white students who experienced disabling life experiences similar to those experienced by the African American students in this study may be more likely to experience the college environment as a nurturing one.

"Students who are empowered by their school experiences develop the ability, confidence, and motivation to succeed" (Cummins, 1993, p. 106). Accordingly, some students may display a lack of motivation and belief in themselves because the educational atmosphere arouses defensive reactions that interfere with intellectual performance (Eleming, 1984; Steele, 1992). For example, the male students in this study were constantly challenged to deal with the negative perceptions and reactions of others toward them based on their identity as African American males. Because school often serves as a viable source of selfesteem for students, African American students may disidentify with school when faced with disempowering 
experiences such as the ones described by the students in this study (Steele, 1992). Students from dominated groups often are disempowered by schools because of the situations they experience inside and outside of the classroom setting. The students in this study described how they understood resiliency in the context of their own lives, and how and why they believed they were resilient. They spoke further about the obstacles they surmounted and the risks they took in overcoming those obstacles, which for others these events could have been immobilizing. They talked about the challenges they faced in the past and the issues they imagine they will continue to contend with in the future. They did not specifically mention their spirits, but when I asked them how they were able to overcome certain life events, several of the students initially responded with comments like "it's just something inside" that helps them remain resilient. They also spoke about the present and the importance of education in their lives. To me, it was their spirits that allowed them to remain self-efficacious and to excel. This was something that surfaced repeatedly in the research process and I felt it was present in each of the eight students.

As the idea of spirit emerged during the research process, I reflected on what the students told me about professors whom they trusted and felt were effective in 
educating them. The students described the people who were able to reach them. They defined how much easier it was for them to learn in classes where the professor was able to relate to them. They talked about trust and the connections they had with other adults in the college community who supported their growth as young adults. The students felt it was much easier to learn when they had positive relationships with professors.

One student was able to describe what that was like when she told me she had a couple of professors who "made a lot of eye contact" and affirmed her presence in the classroom. Another student told me she felt very comfortable with one of her professors who displayed signs and wore $\mathrm{T}$ shirts bearing insignias in support of other minority students on campus. Other students mentioned that when the professors took the time to get to know them, they were more Iikely to ask questions and become actively involved in classroom discussions. What is critical about these relationships is that the students felt nurtured because people in the university community affirmed them and invested confidence in them (Anderson, 1989).

Many professors are unaware that they can contribute positively or negatively to the adjustment of students (Haynes \& Comer, 1990). However, the students indicated how their sense of self-efficacy was strengthened by learning 
about African American culture and other successful African Americans. Professors who created an atmosphere in which the students felt safe to examine issues of race and culture were viewed as effective. The data also revealed that the students struggled in classes where they perceived the professors as biased, uncaring or insensitive. In addition, the students often perceived hostility toward them by other members of the campus community. If the source of selfefficacy is spirit and the strength of their spirits is what keeps these students going, it seems reasonable to expect an educational institution to provide an atmosphere of nurturance.

By examining the research on resilient students and taking into consideration the needs of African American students, colleges and universities can begin to improve opportunities for these students to experience success by structuring programs and teaching practices that accomplish the goal of nurturance. Of course, it is the people who work in universities and colleges that shape educational institutions. It is up to professors, administrators and university personnel to find ways to nurture the students who attend their institutions.

"Nurture" is defined by Webster as: "training, upbringing; something that nourishes; the sum of the influences modifying the expression of the genetic 
potentialities of an organism; to supply with nourishment; educate; to further the development of; and foster" (Merriam-Webster's Collegiate Dictionary, 1995).

Interestingly enough this definition closely correlates with a positive philosophy of education. Some young people will have someone in their lives who provides a nurturing environment; others will not. By the time students enter institutions of higher learning, they will have had experiences that shaped them into the young adults they are. But the mission of higher education is to educate and prepare students to make successful transitions into the world of responsibility as they seek employment, raise families and become productive members of society. This means that we should work to teach and learn from all students regardless of their experiences, culture, race or ethnicity.

This research demonstrates that what we do as professionals in higher education can go a long way in positively or negatively influencing and shaping young people as they enter a world that is becoming increasingly more diverse. Is it not then our obligation as responsible educators to reach out to students and learn to understand others who may not look, think or act as we do so that we can promote to all of our students the ideals of embracing difference? A meaningful education would allow all students 
to critically reflect and challenge the current educational system and policies that continue to oppress large numbers of people in this country. Moreover, we must find ways to nurture those students who do not feel welcome at colleges and universities. Claude steele (1992) utilizes the term wise schooling to describe schools that see promise and value in African American students and act on this insight. Steele (1992) believes "it is not what is taught but what is not taught, what teachers and professors have never learned the value of, that reinforces a fundamental unwiseness in American schooling" (p. 75). I believe wise schooling involves the re-examination of ourselves and the institutions that we are a part of.

As a result of her research with young people from disempowered communities, Nieto (1996) believes students are "asking us to look critically not only at structural conditions, but also at individual attitudes and behaviors. This implies that we need to undertake a total transformation not only of our schools, but also of our hearts and minds" (p. 57). To take this step, educators can begin by examining their own personal beliefs, because biases can often effect the interactions between the students and teachers (Durodoye \& Hildreth, 1995; LadsonBillings, 1994). One student told me he was searching for professors who truly embraced differences in people and had 
the desire to learn more about others, not because someone mandated it, but because they really cared. And as he put it, they would not always be "stuck in their own culture." Based on data from the students in this study as well as data from previous studies, it is important that students be included in the dialogue about schooling and the impact the educational system has on them as individuals and as cultural groups in this country (Nieto, 1996; Maher \& Tetreault, 1994; Fine, 1989).

\section{Implications}

The resiliency research indicates the benefits of protective factors such as self-efficacy and trust in the lives of resilient college students. However, most of the research to date has implications for educators in the $\mathrm{K}-12$ system. Those $\mathrm{K}-12$ schools who are interested in student development and resiliency are encouraged to identify the protective processes and mechanisms in their schools that reduce risk and foster resilience (Winfield, 1991). The resiliency experts suggest schools provide students with instructional strategies that provide evidence of academic success in order to promote their self-efficacy; show students that they are valued members of the community; reinforce feelings that they have made significant contributions to their community, and make students feel 
empowered by celebrating their achievements (Henderson \& Milstein, 1996; McMillian \& Reed, 1994; Sagor, 1996).

Creating this environment in higher education seems to be a daunting task. Certainly, more research is necessary in this area. However, it is possible to modify some of the aforementioned strategies into a usable model for higher education. Many colleges and universities currently address these goals through campus programming efforts and curriculum design. These programs undoubtedly reach a large number of students on these campuses. In some instances the students in this study did feel empowered by school experiences or happy when they could make a contribution to the college community through athletic involvement or other extra-curricular activities. Yet this research demonstrates that these experiences were often overshadowed by other experiences wherein the students did not feel respected or valued by members of the college or university community. Therefore, one can assume that not all students are being reached by these efforts.

The students in this study are resilient and this can be attributed to several qualities each of them possesses. But they do not view the academic institution as a place where protective mechanisms are available to foster their resilience. Furthermore, they do not always feel Iike welcomed and valued members of the campus community. Nor do 
they feel people recognize their experiences and culture as significant. It is reasonable to assume that this is due to their perspectives as African American students. Perhaps additional models for faculty development and student programming will be more effective in supporting students with diverse backgrounds, experiences and perspectives. It is not surprising that there are differences between the adjustment and academic progress of African American students attending historically Black colleges (HBCs) and those attending predominately white institutions (PWIS) (Fleming, 1984). African American students attending HBCs feel a sense of academic progress and a closer connection to students, professors, staff members and professional counselors. As a result of this and several other factors, African American students at HBCs exhibit higher levels of intellectual, social and emotional development than African American students attending PWIs (Fleming, 1984). "From the evidence provided by Black students themselves, the problem is one of institutional abandonment, isolation, and bias in the classroom" (Eleming, 1984, p. 155). All of the students in this study talked about having to deal at one time or another with the difficulty of being the only African American student in the class. Additionally, the students who took classes relating to African American culture felt more comfortable in these classes than in most of their 
other classes because they were not the only African American students in the class. They also expressed positive feelings about the significance of learning more about their own cultural history and the relationship of this knowledge to them personally.

Giving students the opportunity to draw upon their own experiences can be a powerful way to help them question the ideological nature of these experiences and their effects on them in the context of the larger society (Nieto, 1996; Giroux, 1981). Also, dialogue with the students gives them opportunities to validate their own experiences /Giroux, 1981). The students in this study were included in this dialogue about schooling and their experiences with school, specifically in the context of higher education. Their critical views are reflected upon in this dissertation. "It is only by listening to students that we will be able to learn to talk to them. If we believe that an important basis of education is dialogue and reflection about experience, then it is clearly the first step" (Nieto, 1996, p. 55). As critical educators, our purpose must be to reveal to students the forces behind their perceptions and to help students discover the connections between community, culture and the larger societal context (McLaren, 1989).

As I continued to read through research directed at schooling for disempowered students, and the current 
educational practices utilized, I became acutely aware of the similarity between the critical consciousness displayed by the students in this study and what was already written in educational research with respect to educating a culturally diverse student body. And although this study was done specifically with resilient African American students, I believe more students could develop a more critical consciousness through educational practices that consider differences in learning styles, cultures and the personal experiences of every student in the classroom.

Paulo Freire's (1970) approach to learning is based on promoting dialogue between students and teachers who work together in search of a critical consciousness. This consciousness leads to a humane transformation of, rather than a passive accommodations to one's world (McLaren, 1989). Students can draw on their own cultural histories, neighborhood experiences and perceptions of their place in the world to investigate and discuss how they see and experience oppression and social injustice. Freire's theory is based on the assumption that through dialogue students begin to understand their own oppression and reflect critically on the possibilities of new forms of action. Chet Bowers (1987) presents an opposing view as he believes Freire sees dialogue "as the only authentic and mutually emancipatory form of communication" (p. 136). Bowers 
contends that the social world is more complex than Freire's vision of the world as made up of dialogical praxis. He thinks Freire underplays the myriad traditions that form the basis of organizing and sustaining social life: beliefs, practices, institutions, and technologies. Thus he says introducing youth to such social traditions and teaching them how to engage in interaction with already socialized members cannot be achieved indirectly through dialogue (Bowers, 1987). Even if dialogue is not the only way for students and teachers to work toward change, it does appear that the combination of active communication and critical dialogue can bring more persons a step closer to understanding the traditions and structural inequalities that are deeply ingrained in the current educational system. Dialogue may not be enough to give rise to transformation, but it is certainly useful in learning about others' experiences. However, it is equally critical to understand the importance and value of having a minority perspective on campuses and in classrooms. Some educators believe all students benefit from having minority students represented in the classroom (Maher \& Tetrault, 1996; Hill, 1997). When this occurs, issues, policies and practices can be examined through the lens of many different perspectives. Bowers (1987) contends that "in order to question the power relations rooted in the system of social networks 
established and maintained by the state, it is essential for the individual to be able to put issues, policies, and even language itself into a broader perspective" (p. 133).

students and others in the university and college community can begin with a dialogue that is rooted in a deeper understanding of the cultural embeddedness of every individual attending institutions of higher learning.

The resilient African American students in this study displayed an impressive spirit and determination to succeed. They demonstrated that Iife qualities such as trust, selfefficacy and many others previously mentioned, are a part of what helps each one of them achieve. What they also revealed was how important it is to them and for their success in higher education to be affirmed and understood by those in the university and college system. The theory that evolved from the study should strongly encourage educators to take a closer look at themselves, their teaching practices and their institutions so that these students and others can grow intellectually, socially and emotionally in an environment that is supportive, nurturing, empowering and stimulating.

\section{Recommendations}

The implications for professionals and educators working in higher education are many. Professionals in 
higher education need to find ways to improve the learning environment for African American and other underrepresented students (Appendix E). This can be done with careful consideration and dialogue about why these students often have difficulties at institutions of higher learning. Changes in the curriculum, faculty development programs, collaboration with outside communities and the inclusion of nontraditional teaching practices may place colleges and universities one step closer to ensuring that all students learn in an environment where their views, experiences and cultures are welcomed. When this occurs, more students may begin to recognize the importance and value of having not only their own, but other student perspectives in the classroom and on the campus.

Transforming the educational system is not an easy task, and some would say that it is not necessary. This research, along with other similar studies, demonstrates the need to make structural changes in the programs and practices that are currently utilized in higher education. This can be achieved if colleges and universities are serious about changing the institutional inequalities that exist in higher education.

At many colleges and universities around the country, changes are taking place. Culturally and ethnically diverse students are often provided programs whose goals are to 
enrich their experience and provide them with ways to connect with other diverse students and staff on campus. While these programs are a tremendous first step and they can provide students with opportunities to connect with others, they currently have little effect on the majority students on campus. Furthermore, some of these programs create hostility due to limited understanding between white students and students of color. In addition to these programs, the agenda in higher education must include curriculum expansion (or even transformation), pedagogy, and faculty development (Bennett, 1995).

Changing demographics in this country and in the schools has prompted many professionals and theorists involved in educational research to reexamine traditional educational approaches in favor of educational reform efforts that are much more inclusive and empowering for all students. Because educational institutions in the United States reflect the power relations that exist within the broader society (McLaren, 1989; Giroux, 1989; Durodoye \& Hildreth, 1995), the interests of the dominant culture class are often implied in the teaching practices that we use (McLaren, 1989) and the institutional policies and practices that we employ. "Teachers and teacher educators, need opportunities to examine much of what is usually unexamined in the tightly braided relationships of language, culture, 
and power in schools and schooling" (Cochran-Smith, 1995, p. 500).

According to Gloria Ladson-Billings (1994), "culturally diverse students' failure in school results from societal conflict and a struggle for power" (p. 16). She advocates culturally relevant teaching which provides students with opportunities to question the structural inequality, racism and injustices that exist in society (Ladson-Billings, 1994).

The primary goal of culturally relevant teaching or culturally responsive teaching (Bowers \& Flinders, 1991) is to assist students to achieve academic excellence while still identifing with their own culture. "This view of education is further grounded on a recognition that an understanding of language and culture will help to illuminate different though interrelated aspects of teaching and learning" (Bowers \& Elinders, 1991, p. 5). Other scholars believe this type of examination must begin with our own individual histories as people and educators as well as our own experiences as members of particular races, classes, and genders in the world (Weiler, 1988; McLaren, 1989; Cochran-Smith, 1995).

As indicated by the students in this study, situations frequently arise where students of color are left with feelings of frustration, resentment and alienation. Not only 
are these incidents discouraging, they continue to disempower students who can offer valuable insights to other students, professors and university personnel. In my experience with students over the years, examples abound of improper and insensitive remarks made by students, teachers and staff members. Just this week, one of the African American students I work with encountered a professor who made comments directed at the intellectual ability of African American people. She came to me angry, disturbed and offended as she discussed several other racist and sexist remarks previously made in his class. She found this incident disturbing given the particular nature and subject of this class: "Business and Society." I provide this information as an example of what is happening in many university and college classrooms. What is most troubling is that in this aforementioned class, the majority of the students are white males who, according to the young woman I spoke with, appear amused by the professor's comments. Such educators are doing a disservice to the young men and women in their classrooms, whose educational experience now include messages that perpetuate the power structures that exist in society.

Educators in the new millennium will be faced with these issues and many more challenges at every educational level. The dialogue about America's schools and how to 
improve them must continue. While opinions vary on how to facilitate progress, there is a general agreement that schools need many structural changes to address issues pertinent to the needs of today's youth (Smith \& Kaltenbaugh, 1996). Often schools and universities focus primarily on cultural sensitivity and engage in programming efforts such as weekly special events to honor and recognize different cultures. While these are laudable practices, "a focus on cultural sensitivity in and of itself can be superficial if it fails to take into account the structural and institutional barriers that reflect and reproduce power differentials in society" (Nieto, 1996, p. 49).

Realizing the vision of educational reform depends on making opportunities and resources available for professors to learn how to support new learning for an increasingly diverse population of students (NCRTL: National Center for Research on Teaching and Learning, 1995). After all, the attitudes and actions of the professoriate are among the greatest influences on curriculum and student life on campus (Lewis \& Altbach, 1997). There are two areas of concern to address with faculty members on campus. Specifically, curriculum development and teaching styles and practices used by the professors. Both reform efforts would require a strong commitment from the president or governing body of any institution. 
Staff and student development programs are currently in place on many campuses across the country. These programs generally include a diversity component with goals of increasing awareness and improving understanding among all members of the university community. However, although these programs are not specifically designed to work with professors to improve teaching effectiveness, they could equip professors with skilis to work with a diverse student population. The cultivation of effective faculty development programs should include a variety of perspectives from the campus community, including students, human relations and student affairs staff members and other faculty members who support educational reform efforts. Collaboration among all constituents would ensure a variety of perspectives and rich dialogue, which would increase the likelihood of program effectiveness. Faculty development programs should be preceded by assessments of faculty readiness and attitudes toward change (Katz, 1991). The pursuit of community amid diversity involves the entire community (Bennett, 1995). In conjunction with faculty development, efforts to restructure the curriculum are integral to advances in educational reform.

Many student groups in colleges and universities across the country have insisted that curriculum changes be made to address the cultural and historical significance of 
minority cultures. Some institutions of higher learning are taking steps toward greater inclusion of ethnic diversity within their curriculum. At the University of California, Berkeley faculty members from over 40 discipines have developed over 265 new courses that analyze the ways in which America's traditions and their interactions have shaped and continue to shape American identity and experience (Choy, 1997). Professors who participate in this approach are required to develop expertise in and teach about ethnic experiences other than their own.

Yet, attitudes among the faculty across the country vary concerning the issues of multiculturalism and racial/ethnic studies in the curriculum (Lewis \& Altbach, 1997). In a study by the Carnegie Foundation for the Advancement of Teaching, close to one fifth of the professoriate expressed opposition to changing the curriculum to ensure exposure to a variety of ethnic and cultural groups (Lewis \& Albach, 1997). Faculty members who are advocates of curriculum restructuring often create informal groups to facilitate change in their common areas of interest. This is a sound practice, but a comprehensive and systematic expansion of the curriculum to include multicultural perspectives requires the participation and commitment of most of the faculty, particularly on predominately White campuses (Bennett, 1995). 
Perhaps the changes can begin in teacher preparation programs at institutions of higher learning where students who later become teachers are taught to reflect on the educational system and their role in its transformation. A serious effort toward preparing teachers to teach in a culturally relevant manner requires a rethinking of the teacher preparation process. To accommodate the needs of an increasingly diverse population, teacher-training programs should include information on different cultures and learning styles, and teaching methods that recognize multicultural learners (Durodoye and Hildreth, 1995; LadsonBillings, 1994; Cochran-Smith, 1995; Nieto, 1996; Comer, Haynes, Joyner \& Ben-Avie, 1996).

$$
\text { Gloria Ladson-Billings (1994) is a professor at the }
$$
University of Wisconsin, Madison where she studied elementary school teachers who she believed were effective in teaching African American students in low-income, predominantly African American school districts. In her book The Dreamkeepers: Successful Teachers of African American Children, she offers insights about curriculum, practices and methods used by teachers who operate their classrooms in culturally relevant ways. Quite often what is considered appropriate or desirable classroom behavior is inductively learned by teachers and students through their own individual experiences. Teachers enter the profession from 
earlier life and school experiences with a set of predispositions about what promising students should know and how they should behave (Clark, 1983). Marilyn CochranSmith (1995), Associate Professor of Education at the University of Pennsylvania, agrees and explores the traditional methods used in teacher education programs. She examines the "ways that we have traditionally initiated students into the discourses and practices of teachingespecially through widespread versions of "the lesson plan" based on linear analysis of objectives and methods for teaching" (p. 494). She provides readers with examples of ways in which student teachers can participate in the community and learn to understand their students' experiences and culture. She suggests a student teacher program that provides ample opportunities to question, reflect on and interpret their own responses to cultural, linguistic and social diversity in their classrooms.

Cochran-Smith (1995) believes that if we hope to "alter a system that is deeply dysfunctional, the system needs teachers who regard teaching as a political activity and embrace social change as part of the job" (p. 494). Many educators regard change as the active restructuring of entire school systems, including the educational organization, training programs, curriculum, and methods (Cohen, 1969; Durodoye \& Hildreth, 1995). 
As a result of educational reform efforts, a partnership developed initially by Southern University at New Orleans and the New orleans Public Schools is being utilized to improve teacher training programs and address the challenges facing education. "The partnership utilizes action research and praxis - a combination of direct practice and reflection of one's own teaching and its effect on learners - as a basis for change" (Smith \& Kaltenbaugh, 1996, p. 72). The partnership, along with the school Development Program (SDP) which is based on the work of James Comer, allows universities and colleges to work closely with their local communities as they collaborate to challenge and rethink the way teachers are being prepared and their eventual impact on the $\mathrm{K}-12$ setting (Smith \& Kaltenbaugh, 1996). The goal of the partnership is to revise and strengthen the preservice education program by including the following: a mentor program, classroom assistant, training sessions for university faculty, curricular enhancement to include cultural diversity, an emphasis on African American student development, and the development of curricula and instructional materials to address the needs of prospective urban educators.

James Comer has worked to assist schools (predominately in urban areas) to improve the teaching and learning aspects of the educational process, which always include an emphasis 
on child development. The theoretical framework for the programs designed by Comer include the following emphases: (a) a commitment to equal educational opportunities for all children to reach their full potential; (b) a commitment to the dominant ideals of our democratic society to embrace the enhancement of the individual, society, and the community; and (c) a commitment to the mental and physical health of children (Smith \& Kaltenbaugh, 1996). Other partnerships currently in practice include: Cleveland Public School district and Cleveland State University partnership; and the San Francisco School District and San Francisco State University partnership.

The Center for Applied Cultural Studies and Educational Achievement (1996) at San Erancisco State University has developed effective instructional strategies for the achievement of educational excellence by African American students. These strategies take into account the cultural precepts and recurring themes of African American learning styles. Other researchers and programs have investigated the characteristics of African American cognitive and learning styles (Shade, 1982; Durodoye \& Hildreth, 1995; Pressley McPhail \& Johnson, 1998). Still others continue to investigate models of education that eradicate traditional practices in favor of a more "learner-centered" approach (Barr, Robert \& Tagg, John, 1995; O'Banion, 1997). This 
paradigm is based on the assumption that educational experiences are designed primarily for learners as students work in collaboration with educators to assume responsibility for their own learning. This method allows students and professors opportunities to explore and learn from each other through experiential exercises and collaboration with others. Students use their own experiences and ways of knowing to shape and influence their learning program. Cross-cultural learning flourishes as students and teachers work together to design instructional strategies that take into account individual differences and experiences.

Those in higher education must continue to find ways to address the diversity of cultures, experiences and learning styles of the students who attend colleges and universities. As we enter the 21 st century, schools that do not promote the diversity of students and student experience may not continue to prosper. Colleges and universities may be more likely to flourish if they include students from all segments of the population, and then provide meaningful experiences for them once they arrive on campus. These institutions may thus become stronger as others begin to recognize the value of knowing and learning from people who do not always look, think or act as they do. 


\section{References}

Anderson, E. C. (1989). What would we do if we really loved the students? In Gorden LaVern Berry \& Joy Asamen (eds.). Black Students. (pp.218-242). Newbury Park, CA : Sage.

Angelou, M. (1986). All Gods Children Need Traveling

Shoes. NY: Random House

Anderson, G. L., \& Herr, K. (1990). The micro-politics of student voices: Moving from diversity of bodies to diversity of voices in schools. In Catherine Marshall (eds.), The New Politics of Race and Gender. (pp.58-68). The Ealmer Press.

Baron, R. (1995). Psychology. Needham Hts., MA: Allyn \& Bacon.

Barr, R. B., \& Tagg, J. (1995, Nov./ Dec.). From Teaching to Learning-A New Paradigm for Undergraduate Education. Change. 13-25.

Bellah, R., Madsen, R., Sullivan, W., Swindler, A., \& Tipton, S. (1991). The Good Society. NY: Vintage Books. Benard, B. (1993). Fostering Resiliency in Kids. Educational Leadership, 51 (3), 44-48. Bennett, C. (1995). Research on Racial Issues in American Higher Education. In James Banks \& Cherry Banks (eds.), Handbook of Research on Multicultural Education. (pp.663-682). NY: Simon and Schuster Macmiliian. 
Blake, H., Saufley,R., Porter, O., \& Melodia, A. (1990). The Challenge of Diversity. A paper published in "Ethics in Higher education". MCMillan Press. (ERIC Document no. ED $363234)$.

Blumer, H. (1969). Symbolic interactionism: Perspectives and Method. London: Prentice Hall.

Bolman, L., \& Deal, T. (1995). Leading With Soul:An Uncommon Journey of Spirit. San Francisco: Jossey Bass. Bond, C.G., (1981). Social Economic Status and Educational Achievement: A Review Article. Anthropology and Education Quarterly, 12, 227-57.

Bowers, C.A., (1987). Elements of A Post-Liberal Theory of Education. NY: Teachers College Press.

Bowers, C.A.\& Flinders, D., (1991). Culturally Responsive Teaching and Supervision: A Handbook for Staff Development. NY: Teachers College Press. Boykin, W. (1994). Harvesting Talent and Culture. African American Children and Educational Reform. In Robert Rossi (ed.), Schools and Students at Risk. (pp.51-69). NY: Teachers College Press.

Brendtro, L. K., Brokenleg, M., \& Van Bockern, S. E. (1990). Reclaiming Youth at Risk. Our Hope for the Future. Bloomington, IN: National Educational Service. Brown, Addie. (1983). Grandparents' perceived roles in Urban extended Black Family Relationships. Doctoral 
Dissertation, United States International University. Dissertation Abstracts International, 44 (01), 0239.

CACSE, The Center Eor Applied Cultural Studies and

Educational Achievement, San Erancisco state

University. (1997). Utilizing Culture in the Achievement of

Educational Excellence for African American Students.

Clark, R. (1983). Family Life and School Achievement.

Why Poor Black Children Succeed or Fail. Chicago: University of Chicago Press.

Cochran-Smith, M. (1995, fall). Color Blindness and Basket Making are not the Answers: Confronting the Dilemmas of Race, Culture, and Language Diversity in Teacher Education. American Educational Research Journal, 32, (3), 493-522.

Comer, J., Haynes, N., Joyner, E., \& Ben-Avie, M. (1996). (eds.). Rallying the whole Village. The Comer Process for Reforming Education. NY., NY: Teachers College Press.

Comer, J. (1980). School Power. NY: The Free Press. Cummins, J. (1993). Empowering Minority Students: A Framework for Intervention. In Lois Weis \& Michelle Fine (eds.), Beyond Silenced Voices. Class, Race and Gender in United States Schools. (pp. 101-117). Albany, NY: State University of New York Press. 
Delpit, L. (1988). The Silenced Dialogue. Harvard Educational Review, 58, 280-298.

Dubois, W.E.B. (1961). The Souls of Black Folks. NY: Fawcett Publications.

Durodoye, B., \& Hildreth, B. (1995, Winter). Learning Styles and the African American Student. Education, 116 (2), 241-247.

Farrell, E. (1994). Self and School Success: Voices and Lore of Inner-City Students. Albany, NY: State University of New York Press.

Fine, M. (1989). Silencing and Nurturing Voice in an Improbable Context: Urban Adolescents in Public School. In Henry Giroux \& Peter McLaren (eds.), Critical Pedagogy, The State and Cultural struggle. (pp. 125-152). Albany, NY: State University of New York Press.

Fleming, J. (1984). Blacks in College. San Francisco: Jossey-Bass, Inc.

Frankl, V. (1975). The Unconscious God. NY: Simon \& Schuster.

Freiberg, J. H. (1994). Understanding Resilience: Implications for Inner-City Schools and Their Near and Far Communities. In Wang, Margaret C. \& Gordon, Edmund w. (eds.). Educational Resilience in Inner-City America. (pp. 151-165). Hillsdale, NJ: Lawrence Erlbaum Assoc. 
Freire, P. (1970). Pedagogy of the Oppressed. NY:

Continuum Publishing Co.

Ford, D. F. (1994, Dec.). Nurturing Resilience in

Gifted Black Youth. Roeper Review. [On-line], vol.17, 80, ff.

Eukuyama, F. (1995). Trust: The Social Virtues and the Creation of Prosperity. NY: The Free Press.

Giroux, H. (1989). Schooling as a Form of Cultural Politics: Toward a Pedagogy of and for Difference. In Henry Giroux \& Peter McLaren (eds.), Critical Pedagogy, the state, and Cultural Struggle. (pp. 125-151). Albany, N.Y: State University of New York Press.

Giroux, H. (1981). Ideology Culture and the Process of Schooling. Philadelphia: Temple University Press.

Garibaldi, A. M. (1991). Blacks in College. In Willie, C.V., Garibaldi, A.M., \& Reed, W.L. (eds.). The Education of African Americans. (pp.93-99). Westport, CT: Auburn House.

Garmezy, N. (1976). Vulnerable and Invulverable

Children: Theory, research and intervention. New York: American Psychological Asociation.

Garmezy, N. (1991, March/April). Resiliency and Vulnerability to Adverse Developmental Outcomes Associated with Poverty. American Behavioral Scientist, 34 (4), 416430. 
Gibson, M., Ogbu, J.(1991). Minority Status and

Schooling: A Comparative study of Immigrant and Involuntary Minorities. New York: Garland.

Gill, W. (1991). Issues in African American Education. Nashville, TN: One Horn Publishers.

Glaser, B. G., (1978). Theoretical Sensitivity. Mill

Valley, CA: The Sociology Press.

Glaser,B.G., \& Strauss, A.L., (1967). The Discovery of

Grounded Theory.Chicago, Il:Aldine Publishing Co.

Gordon, E. W. \& Song, L. D. (1994). Variations in the

Experience of Resilience. In Margaret C. Wang \& Edmund W.

Gordon (eds.), Educational Resilience in Inner-City America

(pp. 27-43). Hilisdale, NJ: Lawrence Erlbaum Assoc.

Gordon, E., \& Yowell, C. (1994). Cultural Dissonance as

a Risk Factor in the Development of Students. In Robert $\mathrm{J}$.

Rossi (ed.), Schools and Students at Risk. (pp.51-69) . NY:

Teachers College Press.

Gordon, K. A. (1995, Aug.). Self Concept and

Motivational Patterns of Resilient African American High

School Students. Journal of Black Psychology. [On-line], vol. 21, 239, ff.

Govindarajan, G. (1991, winter). Enhancing oral

Communication Between Teachers and Students. Education. [On-line], vol.112, 183, ff. 
Graham, S. (1989). Motivation in Afro-Americans. In

Gordon La Vern Berry \& Joy Keiko Asamen (eds.). Black

Students. (pp. 40-68). Newberry Park, CA: Sage.

Gregory, L. W. (1995, Jan.). The Turnaround Process:

Factors Influencing the School Success of Urban Youth. Journal of Adolescent Research. [On-line], vol. 10, 136, ff.

Hale-Benson, J. (1990). Visions for Children: Educating Black Children in the Context of Their Culture. In Kofi Lomotey (ed.), Going to School: The African American Experience (pp.209-222). Albany NY., State University of New York Press.

Hall, M., \& Allen, W. (1989). Race Consciousness Among African American College Students. In Gorden LaVern Berry \& Joy Keiko Asamen (eds.). Black Students. (pp.172-197). Newbury Park, CA: Sage.

Haynes, N. M., \& Comer, J. P. (1990). Helping Black Children Succeed: The Significance of Some Social Factors. In Kofi Lomotey (eds.), Going to School: The African American Experience. (pp.103-112). Albany, NY: State University of New York Press.

hooks, bell (1993). Sisters of the Yam. Boston: South End Press.

hooks, bell \& West, Cornell. (1991). Breaking Bread: Insurgent Black Intellectual Life. MA: South End Press. 
Hornsby, A., Jr. (1972). The Black Almanac. Woodbury,

NY: Barron's Educational Series.

Jackson, J. S., McCullough, W. R., \& Gurin, G. (1997). Family, Socialization Environment, and Identity Development in Black Americans. In Harriette Pipes McAdoo. (eds.), Black Families. (pp.251-263). Thousand Oaks, CA: Sage.

Katz, J. (1991). White Faculty struggling with the Effects of Racism. In P.G. Altbach \& K. Lomotey (eds.), The Racial Crisis in American Higher Education (187-196). Albany NY: University of New York Press.

Knowles, L.L., \& Prewitt, K. (1969). Institutional

Racism in America. Englewood Cliffs, NJ: Prentice-Hall. Ladson-Billings, G. (1994). The DreamKeepers:

Successful Teachers of African American Children. San Francisco: Jossey-Bass.

Lahey, B. B. (1995) - Psychology: An Introduction. Dubuque, IA: Brown and Benchmark.

Lee, C., \& Slaughter-Defoe, D. (1995). Historical and Sociocultural Influences on American Education. In James Banks \& Cherry Banks (eds.), Handbook of Research on Multicultural Education (pp. 348-371). NY: Simon and Schuster Macmillan

Lincoln Y.S., \& Guba E.G., (1985). Naturalistic Inguiry. Beverly Hills, CA: Sage. 
Locust, C. (1988). Wounding the Spirit: Discrimination and Traditional American Indian Belief Systems. Harvard Educational Review, 58, 315-330.

Maher, F., \& Tetreault Thompson, M. K. (1994). The Feminist Classroom. NY: Basic Books.

Masten, A. S. (1994). Resilience in Individual

Development: Successful Adaption Despite Risk and Adversity. In Margaret C. Wang \& Edmund W. Gordon (eds.), Educational Resilience in Inner-City America (pp. 3-25). Hillsdale, NJ: Lawrence Erlbaum Assoc.

Maxwell, J. (1992). Understanding and Validity in Qualitative Research. Harvard Educational Review, 62, 279296.

McEwen, M.K., Roper, L.D., Bryant, D.R., \& Langa, M.J. Incorporating the Development of African American Students into Psychosocial Theories of Student Development. Journal of College Student Development, 31, 429-436. McIntosh, P. (1998). White Privilege and Male Privilege: A Personal Account of Coming to see Correspondences Through Work in Women's Studies. Unpublished manuscript. Center for Research on Women. Wellesley College. McLaren, P. (1989). Life in Schools: An Introduction to Critical Pedagogy in the Foundations of Education. White Plains, New York: Longman Inc. 
McMillan, J. H., \& Reed, D. F. (1994, Jan./Feb.). AtRisk Students and Resiliency: Factors Contributing to Academic Success. The Clearing House 67 (3), 137-140.

Merriam, S. B.(1988). Case Study in Education. San

Francisco, CA: Jossey Bass.

Merriam-Webster's collegiate dictionary (tenth ed.). (1995). Springfield, MA: Merriam-Webster.

Mickelson, R. A., \& Smith, S. S. (1989). Inner City social Dislocations and School Outcomes: A Structural Interpretation. In Gordon LaVern Berry \& Joy Keiko Asamen (eds.). Black Students. (pp. 99-119). Newbury Park, CA: Sage.

Montgomery, A. F. \& Rossi, R. J. (1994). Becoming at Risk of Failure in America's Schools. In Robert Rossi (ed.) Schools and Students at Risk (pp.3-22). NY: Teachers College Press.

Myss, C., M.D. (1996). Anatomy of the spirit. NY: Harmony Books.

NCRL: National Center for Research on teacher learning (1995). Learning to Walk the Reform Talk, A Framework for the Professional Development of teachers. College of Education, Michigan State University.

Nieto, S. (1994, Winter). Lessons From Students on Creating a Chance to Dream. Harvard Educational Review, 64 (4), 392-426. 
Nobles, W. (1997). African American Family Life. In Harriette Pipes McAdoo (ed.). Black Families. (pp.8393). Thousand Oaks, CA: Sage.

O'Banion, T. (1997). Creating More Learning-Centered Community Colleges. Paper submitted for the League for Innovation in the Community College, Peoplesoft, Inc.

Ogbu, J. (1978). Minority Education and Caste. New York, New York. Academic Press.

Ogbu, J. (1987). Variability in Minority School Performance: A Problem in Search of an Explanation. Anthropology and Education Quarterly, 18, 312-334.

Ogbu, J. (1997). African American Education. A CulturaEcological Perspective. In Harriette Pipes McAdoo (ed.), Black Families (pp.234-250). Thousand Oaks, CA: Sage.

Pajares, F. (1996). Self-Efficacy Beliefs in Academic Settings. Review of Educational Research, 66, (4), 543-578. Paric, P. J. (1994, April). In the Face of Despair. Christian Century. [On-line], vol. III, 14, ff.

Patton, M. (1990). Qualitative Evaluation and Research

Methods. Newbury Park, CA: Sage.

Pines, M. (1979). Superkids. Psychology Today. pp.5363.

Pressley M.I., \& Johnson, C. (1998, Jan.). Transforming Classroom Practice for African American Learners: Implications for the Learning Paradigm. Paper presented at 
the Second North American Conference on the Learning

Paradigm. Palomar College, San Marcos, CA.

Prillerman, S. L., Myers, H. F., \& Smedley, B. (1989).

Stress, Well-Being and Academic Achievment in College. In

Gordon La Vern Berry \& Joy Keiko Asamen (eds.), Black

Students (pp. 198-217). Newbury Park, CA: Sage.

Ratteray, J. D. (1990). African American Achievement, A

Research Agenda Emphasizing Independent Schools. In Kofi

Lomotey (ed.), Going to School: The African American

Experience (pp.197-208). Albany, NY: State University of New York Press,

Rutter, M., M.D. (1987, July). Psychosocial Resilience and Protective Mechanisms. American Journal of

Orthopsychiatry, 57 (3), 316-333.

Rutter, M., M.D. (1984, March). Resilient Children. Why

Some Disadvantaged Children Overcome their Environment and

How We Can Help. Psychology Today, 57-65.

Sagor, R. (1996, Sept.). Building Resiliency in

Students. Educational Leadership, 54, (1), 38-43.

Sautter, C. (1996, Feb.). Who Are Today's City Kids?

Education Digest $61,(6), 4$.

Seidman, I.E.(1991). Interviewing as Qualitative

Research. NY: Teachers College Press.

Semmes, C. E. (1992). Cultural Hegemony and African

Fmerican Development. Westport, CT:Praeger. 
Shade, B.J. (1982). Afro-American Cognitive Style:

Available in School Success? Review of Educational Research, 52, $219-244$.

Smith, D., \& Kaltenbaugh, L. (1996). University-School Partnership:Reforming Teacher Preparation. In Comer, James., Haynes, Norris., Joyner, Edward., \& Ben-Avie, Michael (1996). (eds.). Rallying the whole Village. The Comer Process for Reforming Education. (pp. 72-97). NY: Teachers College Press.

Smith, T. (1995). The Educational Progress of Black

Students. Findings from "The Condition of Education, 1994". no.2. National Center for Education Statistics. Washington, D.C. (ERIC Document no. ED 385 619).

Steele, C. (1992). Race and the Schooling of Black Americans. Atlantic Monthly, 269, (4), 68-78.

Strauss, A., \& Corbin, J.(1990). Basics of Qualitative

Research. Newbury Park, CA: Sage.

Sudarkasa, N. (1997). African American Families and

Family Values. In Harriette Pipes Mcadoo (ed.), Black

Eamilies. (pp. 9-40). Thousand Oaks, CA: Sage.

Taylor, R. D. (1994). Risk \& Resilience: Contextual Influences on the Development of African-American Adolescents. In Margaret Wang \& Edmund Gordon (eds.), Educational Resilience in Inner-City America, (pp. 119-130). Hillsdale, NJ: Lawrence Erlbaum Assoc. 
Taylor, S. (1993). In the Spirit. NY: Harper Collins.

Tierney, W. G. (1991). Utilizing Ethnographic

Interviews to Enhance Academic Decision Making. In

Fetterman, David (ed.). Using Qualitative Methods in

Institutional Research. (pp.7-21). San Erancisco: Jossey

Bass.

U.S. Dept. of Education, National Center for

Educational Statistics. The Condition of Education, 1995. Washington, D.C.: 1995.

Van Manen, M. (1990). Researching Lived Experience. The

Althouse Press: University of Western Ontario.

Wang, M., Haertel, G., \& Walberg, H. (1994).

Educational Resilience in Inner Cities. In Margaret Wang \&

Edmund Gordon (eds.), Educational Resilience in Inner-City

America, (pp. 45-72). Hillsdale, NJ: Lawrence Erlbaum Assoc.

Werner, E., \& Smith, R. (1989). Vulnerable But

Invincible: A Longitudinal study of Resilient Children and

Youth. New York: Adams, Bannister, Cox.

Werner, E. E., \& Smith, R. S. (1992). Overcoming the

Odds: High Risk Children from Birth to Adulthood. Ithaca,

NY: Cornell University Press.

Wharton, C. R., Jr.(1986). Public Higher Education and

Black America: Today's Crisis, Tomorrow's Disaster? Plenary

Address at a National Urban League Conference, San

Erancisco, CA. July 1986. (ERIC Document no. ED 276 388). 
Weiler, K. (1988). Women Teaching for Change: Gender, Class and Power. N.Y., N.Y: Bergin \& Garvey Publishers. Williams, B., \& Newcombe, E. (1994, May). Building on the Strengths of Urban Learners. Educational Leadership, 51 (8), 75-78.

Willie, C.V., Garibaldi, A.M., \& Reed, W.L., (eds.). The Education of African Americans. (1991). Westport, CT:Auburn House.

Winfield, L. F. (1991, Nov.). Resilience, Schooling and the Development in African-American Youth, A Conceptual Eramework. Education and Urban Society, 24 (1), 5-14. Wolin, S. J., \& Wolin, S. (1993). The Resilient Self: How Survivors of Troubled Families Rise Above Adversity. NY: Villard Books. 


\section{APPENDIX A}

INTERVEW QUESTIONS 


\section{FIRST ROUND INTERVIEW OUESTIONS}

These questions were designed to serve as a guide, the exact words and order of the questions changed during the process of data collection and during the interviews.

1. What does this definition of the word resiliency mean to you?

2. Do you see yourself as someone who is resilient, why?

3. What experiences have you had that challenged you or provided you with opportunities to grow?

4. How do you rely on your experiences now to help you succeed in college?

5. Do you view your life experiences and your school experiences as separate or connected? How? In what ways?

6. What specific things frustrate you about being an African American in a college setting?

7. In what ways could others in your college make your experience more valuable?

8. In what ways do you think your life experiences are similar to the other students in your classrooms?

9. In what ways do you think your life experiences dissimilar to the other students in your classrooms?

10. If I were looking out from your eyes, on your first few days of college, what kinds of things would I see occur? If I could feel what you were feeling, how would I feel?

11. What do you think that your teachers should know about the value of your experiences that could contribute to your success in the classroom?

12. How could your overall experience help someone else in the college setting?

13. In what ways could teachers and administrators learn better to help African American students become more successful in the classroom?

14. What attributes, skills or traits could be taught to students like you, going through the university or college system that could help them be more successful? 
APPENDIX B

CONSENT FORM - INDIVIDUAL INTERVIEW 


\section{University of San Diego \\ Consent to Act as a Research Subject}

Cheryl Getz is conducting a research study on The Relationship Between the Life Experiences of Urban African American College Students and Academic Success. Since I have been selected to participate in this study, I understand that I will be interviewed individually extensively concerning this topic. I further understand that I will be interviewed on more than one occasion.

I also understand that a video- taped group interview will be conducted with seven other college students in the San Diego area. I will be asked to sign an agreement to keep the other students in the study and the information that is discussed in the group interview confidential. I realize, however, that the researcher can not completely guarantee anonymity after the group session has been completed. I further understand that I can remove myself from the study and I do not have to be involved in the group interview.

This data collection will take approximately five hours of time over a period of about four months. Participation in this study should not involve any added risks or discomforts to me except for possible emotional stress and or fatigue that interviews of this nature entail.

My participation in this study is completely voluntary. I am not a minor (I am eighteen years old or older) and I attend a school or university in the San Diego area. I understand that I may refuse to participate or withdraw from the study at any time without jeopardy to myself.

I understand that my research records will be kept completely confidential. My identity will not be disclosed without consent required by law. I further understand that to preserve my anonymity data will be written in such a way that individual differences and interview statements will not disclose my identity. Furthermore, only group data (information consistent with all participants) will be used in any publication of the results of this study. Further, I understand that my school and its location will be concealed as well.

Cheryl Getz has explained this study to me and answered my questions. If I have other questions or research related problems, I can reach Cheryl Getz at xxxx during office hours. Any questions concerning my standing at the University of San Diego, please contact my Dissertation Chair; Mary Abascal-Hildebrand at xxxx.

There are no other agreements, written or verbal, related to this study beyond that expressed on this consent form. I have received a copy of this consent document and "The Experimental Subject's Bill of Rights."

I, the undersigned, understand the above explanations and, on that basis, I give consent to my voluntary participation in this research.

Signature of Subject

Date

Location

Signature of Witness

Date

Signature of Researcher

Date 
APPENDIX C

CONSENT FORM - GROUP INTERVIEW 


\section{University of San Diego \\ Research Participant Agreement of Confidentiality}

I have been involved with research conducted by Cheryl Getz regarding African American students and academic achievement. A part of this study involves a group interview with other students going to school in the San Diego area. This session will be video-taped and the data gathered will be used as part of the analysis process.

I understand that the information disclosed in this meeting could be of a sensitive nature. I further understand and agree that I am expected to maintain confidentiality and keep any information I receive from other students as well as the participants identity confidential. I have been informed by Cheryl Getz that I am free to withdraw from this study without any negative consequences.

By signing this document, I agree to uphold the academic integrity expected of participants and the researcher involved in this study. 
APPENDIX E

\section{RECOMMENDATIONS}

Reproduced with permission of the copyright owner. Further reproduction prohibited without permission. 


\section{SUGGESTED RECOMMENDATIONS}

- Conduct future studies with larger groups of African American students and other students of color to learn the problems they encounter in higher education.

- Encourage similar qualitative studies with professors in higher education to determine their attitudes regarding classroom environments that embrace underrepresented students.

- Investigate the experiences of college adjustment as it relates to African American students from lower socioeconomic environments and those from middle and high income backgrounds, to ascertain the strengths and weaknesses of these learners.

- Study successful historically Black colleges and investigate the possibility of using this information to provide a more validating environment for all students of color at predominately white institutions.

- Provide training programs for faculty and staff to learn about the relationship between a student's culture/experiences and the learning environment/ academic success.

- Encourage professors to demonstrate their support of minority student groups on campus by hanging posters and displaying symbols such as T-shirts or other apparel 
bearing group insignias, as well as by attending

functions sponsored by minority student groups on campus.

- Provide faculty with financial incentives and opportunities to engage in nontraditional teaching practices that take into account the diversity of students in their classrooms.

- Furnish students on campus with a safe place to discuss racial incidents, insensitive teaching practices and biased administrative policies.

- Address student complaints by meeting with professors; initiate inservice training for professors who employ insensitive language and teaching practices.

- Demonstrate commitment to diversity by hiring professors, counselors and administrators of color.

- Provide mandatory educational and training programs for all new employees (staff, administrators and professors).

- Work toward integration at all levels. Create a campus environment that is racially balanced.

- Implement a mandatory class for all first-year students that introduces them to various levels of awareness. This class could explore individual and general biases and might include conflict resolution, problem solving and communication skills in the context of an increasingly diverse world. Make this class one of the general elective requirements. 
- Encourage students of color to become involved in the dialogue concerning the curriculum and learning environment. 